\title{
A TEORIA DOS STAKEHOLDERS NO BRASIL: PRODUÇÃO ACADÊMICA NO PERÍODO DE 2014
}

\author{
A 2019

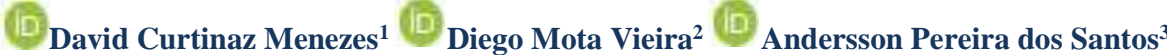 \\ ${ }^{I}$ Mestre em Administração, Universidade de Brasília - UnB. Brasília, Distrito Federal-Brasil. davidcurtinaz@yahoo.com.br \\ ${ }^{2}$ Doutor em Administração, Universidade de Brasília - UnB. Brasília, Distrito Federal - Brasil. diegolmv@yahoo.com.br \\ ${ }^{3}$ Mestre em Administração, Universidade de Brasília - UnB. Brasília, Distrito Federal - Brasil. anderssonpereira@ hotmail.com
}

\section{Resumo}

Objetivo: Analisar o perfil da produção recente sobre Teoria dos Stakeholders nos periódicos nacionais.

Método: Revisão de literatura, na qual foram selecionados 271 artigos publicados, entre 2014 e 2019, em 92 periódicos do estrato superior do Qualis/CAPES em Administração e áreas afins.

Originalidade/Relevância: $O$ conhecimento acerca do referido perfil auxilia os pesquisadores a visualizarem aspectos metodológicos e conceituais a partir dos quais o tema está sendo discutido, contribuindo para a definição de uma agenda de pesquisa.

Resultados: A RBGN, a RAUFSM e a RIAE são os periódicos de referência. A maioria dos estudos adota uma abordagem teórico-empírica e possui natureza qualitativa, sendo a pesquisa documental e a entrevista os instrumentos de coleta de dados mais utilizados. A análise de conteúdo foi a técnica de análise de dados mais aplicada. A definição de Stakeholder de Freeman e o modelo de análise de Mitchell, Agle e Wood são os mais empregados. A pesquisa sobre o tema é crescentemente colaborativa, bem como foi possível constatar a validação das Leis de Bradford e Zipf, mas não a de Lotka. Portanto, é possível identificar um grupo de periódicos mais devotos ao tema e os termos que apresentam maior frequência nos artigos pesquisados. Entretanto, não foi possível comprovar que uma larga proporção da literatura foi produzida por um pequeno número de autores. Contribuições teóricas/metodológicas: Foram identificadas lacunas na literatura e tendências, como o diálogo entre a Teoria de Stakeholder e a geração de valor, que foram objeto da agenda de pesquisa sugerida.

Palavras-chave: Teoria dos stakeholders. Produção acadêmica. Periódicos científicos brasileiros.

\section{THE STAKEHOLDER THEORY IN BRAZIL: ACADEMIC PRODUCTION IN THE PERIOD FROM 2014 TO 2019}

\section{Abstract}

Objective: To analyze the profile of recent production on Stakeholder Theory in national journals.

Method: Literature review in which 271 articles published between 2014 and 2019 were selected in 92 journals in the upper stratum of Qualis / CAPES in Administration and related areas.

Originality / Relevance: The knowledge about this profile helps researchers to visualize methodological and conceptual aspects from which the theme is being discussed, contributing to the definition of the research agenda.

Results: RBGN, RAUFSM and RIAE are the reference periodicals. Most studies adopt a theoretical-empirical approach and have a qualitative nature, with documentary research and interviews are the most used data collection instruments. Content analysis was the most applied data analysis technique. Freeman's definition of Stakeholder and Mitchell, Agle and Wood's model of analysis are the most used. Research on the topic is increasingly collaborative, and it was possible to verify the validation of the Laws of Bradford and Zipf, but not the Law of Lotka. Therefore, it is possible to identify a group of journals most devoted to the topic and the terms that are more frequent in the researched articles. However, it was not possible to prove that a large proportion of the literature was produced by a small number of authors
Theoretical / methodological contributions: Gaps were identified in the literature and trends such as the dialogue between the Stakeholder Theory and the generation of value which were the subject of the suggested research agenda.

Keywords: Stakeholder Theory. Academic production. Brazilian scientific journals.

\section{LA TEORÍA DE LOS STAKEHOLDERS EN BRASIL: PRODUCCIÓN ACADÉMICA EN EL PERÍODO DE 2014 A 2019}

\section{Resumen}

Objetivo: analizar el perfil de la producción reciente sobre Teoría de los Stakeholders en revistas nacionales.

Metodología: revisión de la literatura, en la que se seleccionaron 271 artículos publicados entre 2014 y 2019 en 92 revistas del estrato superior de Qualis / CAPES en Administración y áreas afines.

Originalidad / Relevancia: el conocimiento de este perfil ayuda a los investigadores a visualizar los aspectos metodológicos y conceptuales desde los que se discute el tema, contribuyendo a la definición de una agenda de investigación.

Resultados: RBGN, RAUFSM y RIAE son las revistas de referencia. La mayoría de los estudios adoptan un enfoque teórico-empírico y tienen un carácter cualitativo, siendo la investigación documental y las entrevistas los instrumentos de recolección de datos más utilizados. El análisis de contenido fue la técnica de análisis de datos más aplicada. La definición de Freeman de Stakeholder y el modelo de análisis de Mitchell, Agle y Wood son los más utilizados. La investigación sobre el tema es cada vez más colaborativa y fue posible verificar la validación de las Leyes de Bradford y Zipf, pero no la de Lotka. Por tanto, es posible identificar un grupo de revistas más dedicadas al tema y los términos más frecuentes en los artículos investigados. Sin embargo, no fue posible demostrar que una gran proporción de la literatura fuera producida por un pequeño número de autores.

Aportes teóricos / metodológicos: se identificaron vacíos en la literatura y tendencias, como el diálogo entre la Teoría de los Stakeholders y la generación de valor, que fueron el tema de la agenda de investigación sugerida.

Palabras-chaves: Teoría de los stakeholders. Producción académica. Revistas científicas brasileñas.

\section{Cite as / Como citar}

American Psychological Association (APA)

Menezes, D. C., Vieira, D. M., \& Santos, A. P. (2020, Oct./Dec.). A teoria dos stakeholders no brasil: produção acadêmica no período de 2014 a 2019.

Iberoamerican Journal of Strategic Management (IJSM), 19(4), 119-150. https://doi.org/10.5585/riae.v19i4.17345. 


\section{Introdução}

A Teoria dos Stakeholders visa chamar a atenção dos gestores para a importância de gerenciar os interesses de grupos ou indivíduos que podem afetar ou serem afetados pelas ações da organização. Esse aspecto é realçado no que parece ser a definição mais utilizada de Stakeholder, a de Freeman (1984). Em função desse papel desempenhado pelos Stakeholders, o autor recomenda que seja elaborado um mapa com os principais atores que podem influenciar a organização. Para tanto, é necessário identificar tais atores e, por isso, são apresentados, no presente estudo, alguns dos modelos de identificação e análise de Stakeholders mais recorrentes na literatura.

Em razão da importância da compreensão sobre o papel dos Stakeholders nas organizações, verifica-se o número crescente de pesquisas sobre o tema. Por isso, é relevante compreender como o assunto tem sido tratado nas publicações em periódicos nacionais. Deste modo, o presente estudo tem por objetivo analisar a produção acadêmica acerca desse campo teórico, com base na seguinte pergunta: qual é o perfil da produção acadêmica sobre a Teoria dos Stakeholders no Brasil no período entre 2014 e 2019? Para responder à essa pergunta foram examinados artigos publicados em periódicos nacionais enquadrados nos estratos mais altos do Qualis/CAPES (A2 a B2) em Administração e áreas afins. Não foi escolhido o estrato A1, pois não há periódico nacional classificado em tal estrato na área de Administração.

Para o alcance do objetivo mencionado, realizou-se uma revisão de literatura na qual foram selecionados artigos publicados, entre 2014 e 2019, em periódicos do estrato superior do Qualis/CAPES em Administração e áreas afins. A referida revisão permitiu obter informações sobre o perfil da produção acadêmica supracitado.

Assim, por exemplo, foi identificado que: i) a Revista Brasileira de Gestão de Negócios (RBGN), a Revista de Administração da Universidade Federal de Santa Maria (RAUFSM) e a Revista IberoAmericana de Estratégia (RIAE) são os periódicos de referência; ii) predominam os estudos que adotam uma abordagem teórico-empírica e possuem natureza qualitativa, sendo a pesquisa documental e a entrevista os instrumentos de coleta de dados mais utilizados; iii) a análise de conteúdo é a técnica de análise de dados mais aplicada; iv) a definição de Stakeholder de Freeman (1984) e o modelo de análise de Mitchell, Agle e Wood (1997) são os mais empregados; e v) os termos Stakeholders, governança, responsabilidade social, estratégia e gestão são os mais utilizados.

Além disso, foram adotadas técnicas de pesquisa bibliométrica, tendo em vista que os resultados foram analisados sob a ótica das leis clássicas da bibliometria (leis de Lokta, Bradford e Zipf). Dessa forma, foi possível obter informações sobre a produtividade dos autores e dos periódicos científicos, bem como acerca dos termos mais recorrentes nos artigos pesquisados.

Identificou-se lacunas e tendências na literatura, como o diálogo entre a Teoria de Stakeholder e a geração de valor, que é objeto da agenda de pesquisa sugerida ao final do presente trabalho. Desse modo, os resultados ressaltam a importância do presente estudo, pois o conhecimento acerca das publicações sobre 
Stakeholders no Brasil pode auxiliar os pesquisadores a visualizar aspectos metodológicos e conceituais a partir dos quais o tema está sendo discutido e contribuir para a definição de uma agenda de pesquisa.

Cumpre ressaltar que as pesquisas dessa natureza são úteis para conhecer um determinado assunto, sobretudo quando o campo de conhecimento em questão caracteriza-se por ter amadurecido apenas recentemente (Ribeiro \& Costa, 2017a), sendo que a sua validação empírica ainda é incipiente em algumas de suas proposições (Barbero \& Marchiano, 2016).

$\mathrm{O}$ artigo se estrutura, além desta introdução, em outras quatro seções. Na próxima seção, serão apresentados os conceitos básicos da referida teoria. Posteriormente, será demostrado o método empregado no presente trabalho, seguido pela apresentação dos resultados obtidos. Por fim, são apresentadas as considerações finais e as recomendações para pesquisas futuras.

\section{Referencial teórico}

A Teoria dos Stakeholders tem ganhado destaque no ambiente acadêmico e empresarial, sendo, inclusive, objeto de discussão no Fórum Econômico Mundial em 2020, em que foi articulada a necessidade de reformar o capitalismo em direção ao stakeholder capitalism, ou seja, ao capitalismo que considera os interesses de diversos atores (Stakeholders) em substituição a um capitalismo que prioriza acionistas (Mascena \& Stocker, 2020). Isso porque, desde a crise financeira global de 2008, há a demanda da sociedade por um capitalismo mais responsável, de modo que a Teoria de Stakeholders tem encontrado cada vez mais conexão com a prática organizacional (Freeman, Phillips \& Sisodia, 2020).

A Teoria dos Stakeholders foi concebida em um contexto de produção capitalista tradicional em que a empresa estava relacionada apenas a quatro grupos: fornecedores, funcionários, acionistas e clientes (Mainardes \& Raposo, 2011). Ocorre que, conforme apontado por Freeman (1984), há outros grupos que são influenciados pelas atividades da empresa, de modo que a organização passa a ser o centro de uma série de relações interdependentes.

Nesse contexto, a referida teoria visa demonstrar a importância dos relacionamentos da organização com diversos atores, como clientes, fornecedores, empregados e comunidades, o que representa uma mudança de paradigma, pois, dessa forma, questiona-se a tese de que o objetivo fundamental dos negócios é proporcionar riqueza aos acionistas. Assim, a teoria defende que a firma deve criar valor para todas as partes interessadas e não apenas para os acionistas (Freeman, 2020).

Vale ressaltar que, embora o assunto tenha sido objeto de trabalhos realizados na década de 1980 , como o de Freeman (1984), o tema ainda é atual, haja vista que, conforme afirma o autor (Freeman, 2020), a gestão de Stakeholders ainda é importante no século XXI, uma vez que a sobrevivência das organizações depende da capacidade de gerenciar os relacionamentos com ampla rede de atores.

Segundo Carroll e Buchholtz (2011), uma gestão eficaz de Stakeholders requer a adoção de medidas que respondam às questões fundamentais, como: i) quem são Stakeholders; e ii) quais estratégias ou ações a organização deve tomar com respeito a esses atores. Nesse contexto, é necessário identificar tais 
atores e as estratégias por eles adotadas para influenciar a organização, o que nos remete às definições de Stakeholder e aos modelos de identificação e análise desses atores mais recorrentes na literatura, os quais são descritos a seguir.

\subsection{Definição de stakeholder}

Há diversas definições na literatura, a mais antiga é a associada ao Stanford Research Institute (SRI) que, em 1963, como citado em Freeman (1984, p. 31), definiu Stakeholders como "os grupos dos quais, sem o suporte, a organização não poderia existir". Posteriormente, a referida definição foi aprimorada por outros atores como Freeman (1984), para quem a definição do SRI era insatisfatória, pois continha conceitos genéricos, como sociedade, por exemplo, e não retratava adequadamente a segmentação existente no que tange aos diferentes interesses entre os diversos grupos sociais.

Por isso, ele menciona duas novas definições: ampla e restrita. De acordo com a definição ampla, Stakeholder é qualquer grupo ou pessoa que pode afetar e ser afetado pelo desenvolvimento das atividades da organização (Freeman, 1984), e é reconhecida como a definição clássica (Ribeiro \& Costa, 2017a). Segundo a definição restrita, Stakeholders são aqueles grupos dos quais a organização depende para sobreviver. Ainda, esses atores podem estar dentro ou fora da empresa e têm interesse no problema em questão e na sua solução (Mason \& Mitroff, 1981).

Posteriormente, uma nova definição foi formulada, com o intuito de chamar a atenção para o fato de que Stakeholder é pessoa, grupo ou organização que pode reivindicar a atenção, os recursos ou os outputs de uma organização, ou que pode ser afetado por tais outputs (Bryson, 1988). Na década de 1990, outras definições foram concebidas com o objetivo de esclarecer que os interesses desse ator são urgentes ao negócio e que, por isso, a empresa deve dar satisfação a ele (Carroll, 1991), pois trata-se de um grupo ou indivíduo que tem interesse nas ações de uma organização e tem a capacidade de influenciá-la (Savage, Nix, Whitehead \& Blair, 1991).

Além disso, esse ator possui interesses legítimos de participar da organização (Donaldson \& Preston, 1995), podendo reivindicar ou dispor de propriedade, direitos ou interesses nessa empresa e em suas atividades no período passado, presente e futuro (Clarkson, 1995). Além disso, esse ator possui afinidade com a organização e tende a receber um tratamento diferenciado em relação ao conferido a outros atores sociais (Phillips, 1997).

Na década de 2000, foram criadas definições que contribuíram para esclarecer que os Stakeholders exercem poder e influência (Bourne \& Walker, 2005), pois podem usar o poder para influenciar o comportamento e o desempenho das organizações (Gomes \& Gomes, 2007). Esses atores também criam e capturam valor econômico em suas interações com a organização (Garcia-Castro \& Aguilera, 2015). 
Menezes, D. C., Vieira, D. M., \& Santos, A. P. (2020, Oct./Dec.). A teoria dos stakeholders no brasil: produção acadêmica

Tabela 1 - Evolução da definição de Stakeholder

\section{Definição de Stakeholder}

\begin{tabular}{cl}
\hline Década de 1960 & $\begin{array}{l}\text { Ator sem o suporte do qual a organização não poderia existir (Stanford Research } \\
\text { Institute, 1963 como citado em Freeman, 1984, p. 31) }\end{array}$ \\
\hline Década de 1980 & $\begin{array}{l}\text { Ator que pode afetar e ser afetado pelas atividades da organização (Freeman, } \\
\text { 1984), seja mediante ações, comportamentos ou políticas, que tem interesse no } \\
\text { problema e na sua solução (Mason \& Mitroff, 1981), e pode reivindicar a atenção, } \\
\text { os recursos ou os outputs da organização (Bryson, 1988). }\end{array}$ \\
\hline
\end{tabular}

Ator com o qual a organização se relaciona que reivindica ou dispõe de Década de $1990 \quad$ propriedade e direitos sobre as atividades da organização (Clarkson, 1995), cujo tratamento diferenciado (Philips, 1997), e que possui interesse legítimo de participar da organização (Donaldson \& Preston, 1995).

\section{Década de 2000 \\ Ator que possui poder e influência (Bourne \& Walker, 2005), pois usa o poder para influenciar o comportamento e o desempenho da organização (Gomes \& Gomes, 2007). Esse ator cria e captura valor econômico em suas interações com a organização (Garcia-Castro \& Aguilera, 2015).}

Fonte: Elaborada pelos autores.

Conforme depreende-se da Tabela 1, a definição de Stakeholder evoluiu de uma caracterização mais genérica (afetar ou ser afetadpo), para outras que mencionam aspectos específicos e auxiliam na caracterização desse ator (detenção de direitos de propriedades ou recursos da organização). Dessa forma, a multiplicidade de definições existentes parece ser uma decorrência do fato de que os teóricos tendem a captar diversos aspectos referentes à relação entre os Stakeholders e a organização. Além disso, parece haver uma construção conjunta, de modo que novas definições buscam complementar ou aperfeiçoar as antigas.

Nesse sentido, por exemplo, Nóbrega e Cândido (2015), ao analisar as diversas definições, afirmam que Carroll (1991) dá ênfase a um aspecto pragmático, o poder que o Stakeholder possui de afetar os objetivos de desempenho da empresa. A esse aspecto foram acrescidas, por Mitchell, Agle e Wood (1997), a urgência de sua reivindicação e a legitimidade do relacionamento do ator com a organização, de modo a constituir o modelo de análise mais utilizado nos artigos que compõem a amostra dessa pesquisa.

Assim, segundo Mitchell et al. (1997), Stakeholder é qualquer grupo ou indivíduo que detenha, pelo menos, um dos seguintes atributos: legitimidade, poder e urgência. Some-se a isso o fato de que as diversas definições servem a propósitos diferentes, bem como o que pode fazer um ator ser considerado parte interessada pode variar de uma organização para outra (Parmar, Freeman, Harrison, Wicks, Purnell \& Colle, 2010).

\subsection{Identificação e análise de stakeholders}

Existem várias formas de categorizar Stakeholders, alguns dos modelos de análise foram citados nos artigos que compõem a amostra da pesquisa e serão explicados nessa seção. São eles: Freeman (1984; 
2010); Savage et al. (1991); Clarkson (1995); Donaldson e Preston (1995); Mitchell et al. (1997); Frooman (1999); Andriof e Waddock (2002); Friedman e Miles (2006); Olander (2007); Curzon (2009); Reed, Graves, Dandy, Posthumus, Hubacek, Morris, Prell, Quinn e Stringer (2009); Gomes, Liddle e Gomes (2010); Carroll e Buchholtz (2011); Harrison e Bosse (2013) e Schepper, Dooms e Haezendonck (2014).

Freeman (1984) classificou os Stakeholders em internos e externos. Os internos são os responsáveis pelo alcance dos objetivos da organização como, por exemplo, os colaboradores da empresa. Os externos são aqueles afetados pela atuação da organização, mas que não participam do projeto organizacional, como é o caso dos consumidores.

Savage et al. (1991) apresentam um modelo que leva em consideração a capacidade de cooperação e o potencial que o ator possui para ameaçar a organização. De acordo com esse modelo, os atores são classificados como: a) apoiadores (baixa ameaça potencial à organização e alto potencial cooperativo); b) marginais (não são nem altamente ameaçadores nem especialmente cooperativos); c) não apoiadores (grande ameaça potencial e um baixo potencial de cooperação); e d) mixed blessing (alto potencial para ameaçar bem como para cooperar).

Clarkson (1995) classificou os Stakeholders em primários e secundários. Os primários estão associados diretamente à sobrevivência da organização (ex.: empregados). Por outro lado, os secundários são aqueles que influenciam ou são influenciados pela empresa, porém não são essenciais para sua sobrevivência, pois eles não estão envolvidos nas transações da organização, sendo, por isso, considerados menos essenciais (Ribeiro \& Costa, 2017a). Vale salientar que essa forma de diferenciar as partes interessadas também foi usada por Freeman (2010), o qual sustenta que os atores primários são aqueles que se relacionam diretamente com a organização (empregados, fornecedores, financiadores, comunidade local e clientes), enquanto os atores secundários são aqueles que afetam os atores primários e incluem os grupos de interesse, os meios de comunicação e os grupos de defesa do consumidor.

Deve-se ressaltar que essa nomenclatura (primário e secundário) foi retomada por Curzon (2009), o qual, entretanto, acrescentou uma nova categoria, o ator terciário. Assim, para Curzon (2009), os primários são atores com alto nível de poder, envolvimento e influência em todas as etapas do processo. Os secundários possuem menor capacidade de influenciar o processo de tomada de decisão, pois atuam em um nível inferior, que está voltado para o gerenciamento local do projeto. Os terciários não estão diretamente envolvidos no processo de tomada de decisões, nem podem influenciá-lo diretamente. Assim, tais atores recorrem aos atores primários ou secundários para que as suas reivindicações sejam atendidas (Silva, Shibao, Santos \& Barbieri, 2019).

A classificação proposta por Clarkson (1995) parece ter influenciado também a tipologia proposta por Reed et al. (2009), os quais também se utilizam da lógica da segmentação de Freeman (1984), ou seja, a de diferenciar os atores internos e externos. Assim, segundo Reed et al. (2009), os atores podem ser: primários, secundários e externos. Os primários são definidos como os que possuem maior relevância na rede de relações entre atores. Os atores secundários possuem média importância e os atores externos são os 
que possuem menor importância na rede de relações ou menor influência na dinâmica cotidiana da organização (Cardoso, Sobrinho \& Vasconcellos, 2015).

Carroll e Buchholtz (2011) fazem uma adaptação da classificação de Clarkson (1995), de modo a classificar os Stakeholders em primários e secundários, e em sociais e não sociais. Os Stakeholders primários sociais são aqueles que se relacionam e afetam diretamente a organização. Os secundários sociais se relacionam com o negócio de forma indireta, mas detêm influência e poder para afetar os negócios da organização. Os Stakeholders não sociais são o meio ambiente, as gerações futuras e grupos ambientalistas, o enquadramento como primários ou secundários dependerá das circunstâncias do caso concreto, ou seja, se o relacionamento com a organização ocorre de forma direta ou indireta (Nóbrega \& Cândido, 2015).

Donaldson e Preston (1995) propõem que, na classificação de tais atores, sejam considerados três aspectos: descritivo, normativo e instrumental. $\mathrm{O}$ aspecto descritivo se refere ao uso da teoria para explicar características e comportamentos da organização. O aspecto normativo é usado para interpretar as funções da organização, incluindo a identificação de diretrizes para sua operação. Assim, tal aspecto enfatiza que a teoria busca analisar as relações entre a organização e as partes interessadas, com o intuito de prescrever diretrizes sobre como a organização deve tratar os seus Stakeholders.

Nesse sentido, Oliveira, Pontes Junior, Oliveira e Sena (2014) comentam que a Teoria dos Stakeholders tem por objetivo predizer relações de causa e efeito, recomendando práticas sobre a gestão de Stakeholders. O aspecto instrumental é usado para identificar as conexões entre o gerenciamento de Stakeholders e o alcance dos objetivos da organização, ou seja, relaciona eventos específicos associados ao gerenciamento das partes interessadas (causa) com o respectivo efeito sobre o desempenho da organização (Oliveira et al., 2014).

Mitchell et al. (1997) criaram uma tipologia de classificação baseada na posse dos seguintes atributos: a) o poder de influenciar a organização; b) a legitimidade do relacionamento com a organização; e c) a urgência no atendimento do seu interesse. Essa tipologia visa identificar o grau de prioridade concedido pelos gestores às solicitações do Stakeholder (Ribeiro \& Costa, 2017a). Mitchell et al. (1997) dividem as classes de Stakeholders em três grupos: latente, moderadamente saliente e expectante.

O primeiro grupo é composto por aqueles que possuem apenas um dos atributos (adormecido possui poder; arbitrário/discricionário possui legitimidade; e reivindicador possui urgência). O segundo grupo é composto por atores que detém dois atributos (dominante, poder e legitimidade; dependente, urgência e legitimidade; e perigoso, poder e urgência). O terceiro grupo refere-se ao definitivo, que é o Stakeholder mais importante, pois possui poder, legitimidade e urgência, o que confere atenção imediata e prioritária a esse ator. Dessa forma, esse ator é considerado imprescindível para organização (Ribeiro \& Costa, 2017a). Caso não possua nenhum dos atributos, os indivíduos ou as entidades não são considerados Stakeholders.

Deve-se salientar, ainda, que Wood, Mitchell e Agle, autores do artigo publicado em 1997, em conjunto com Bryan, fizeram, recentemente, uma avaliação do impacto do modelo proposto naquela época. Na conclusão, os autores reforçam que a conceituação de Stakeholders depende em grande parte das 
percepções dos gestores, os quais podem ou não perceber com precisão quem são seus Stakeholders e se são importantes, o que pode levá-los a desconhecer ou interpretar incorretamente algumas reivindicações (Wood, Mitchell, Agle \& Bryan, 2018).

Ademais, deve-se salientar que a priorização de atores abordada por Mitchell et al. (1997) continua a integrar a agenda de pesquisa, haja vista o trabalho de Mitchell e Lee (2019), em que é analisada a importância de identificar-se os atores para a criação de valor e sinalizada a necessidade de uma melhor compreensão sobre o dinamismo dos Stakeholders citado por Mitchell et al. (1997), ou seja, a identificação de quando e como esses atores mudam de classificação na tipologia proposta em Mitchell et al. (1997).

Deve-se ressaltar que um desdobramento do modelo de Mitchell et al. (1997) foi proposto por Friedman e Miles (2006), os quais sustentaram que a identificação dos atributos permite estabelecer o nível de prioridade (irrelevante, baixa, moderada e alta) no atendimento aos Stakeholders. Assim, o ator que possui apenas um atributo é considerado de baixa prioridade, o ator que possui dois atributos é considerado de prioridade moderada e o ator que possui os três atributos é considerado de alta prioridade. Por fim, o ator que não possuir nenhum atributo deve ser considerado irrelevante.

Outro modelo derivado da tipologia de Mitchell et al. (1997) é o proposto por Schepper, Dooms e Haezendonck (2014), que atribuem graus de intensidade (baixa, média, alta) aos atributos poder e urgência, a fim de gerar uma matriz por meio da qual são classificados os Stakeholders.

Outro modelo de análise é o de Frooman (1999), o qual descreve as estratégias de influência dos Stakeholders. O autor usou a Teoria da Dependência de Recursos para criar quatro tipos de estratégia. São elas: a) retenção direta; b) uso direto; c) retenção indireta; e d) uso indireto.

As estratégias de retenção de recursos são aquelas em que há uma descontinuidade no repasse de recurso por parte do Stakeholder à firma, com a intenção de promover uma mudança no comportamento dessa última. Um exemplo disso é a greve de funcionários. Nas estratégias de uso, seja direto, seja indireto, o Stakeholder continua a fornecer o recurso, porém com algumas condições. O uso direto ocorre quando o Stakeholder manipula o fluxo de recursos para a firma. Já o uso indireto ocorre quando o Stakeholder, por não controlar o recurso, exerce influência por meio de um aliado que detenha a manipulação do fluxo de recursos. A partir dessas estratégias, Frooman (1999) estabelece quatro tipos de relacionamento entre a organização e o Stakeholder: poder da firma; alta interdependência; baixa interdependência; e poder do Stakeholder.

Andriof e Waddock (2002), por sua vez, classificam os Stakeholders em quatro grupos: regulatórios; organizacionais; comunitários; e meios de comunicação. O primeiro inclui o governo e as agências reguladoras, associações e outras entidades que podem influenciar as normas, interferindo na atividade da organização. O segundo corresponde aos atores diretamente envolvidos com a organização, como é o caso dos clientes. O terceiro grupo se refere às organizações ambientais e sociais. Por fim, o último grupo diz respeito aos meios de comunicação e outras tecnologias usadas para informar a sociedade sobre as ações da organização (Neutzling, Santos \& Barcellos, 2015). 
Deve-se ressaltar que os aspectos abordados na classificação de Andriof e Waddock (2002) parecem dialogar com a classificação proposta por Gomes et al. (2010), os quais sustentam que os Stakeholders podem ser classificados em cinco categorias: regulador, colaborador, legitimador, controlador e formador de agenda. A categoria "regulador" contém os atores que possuem capacidade de incluir requerimentos institucionais e técnicos no processo de tomada de decisões. Essa categoria parece ser convergente com o grupo regulatório citado por Andriof e Waddock (2002).

A categoria "colaborador" é composta por atores que auxiliam o governo local a prestar serviços públicos. A categoria "legitimador" contém os cidadãos e a comunidade local os quais são os usuários dos serviços públicos. Tendo em vista que os usuários são os clientes da política pública, essa categoria parece ser compatível com o grupo organizacional citado por Andriof e Waddock (2002). Além disso, essa categoria contém a comunidade local, a qual é um exemplo do grupo comunitário descrito por Andriof e Waddock (2002).

A categoria "controlador" é composta pelos órgãos de controle e demais atores que têm o poder de exigir que o gestor público preste contas e de obrigá-lo a cumprir algumas regras relacionadas com o uso eficiente de recursos públicos. Essa categoria pode conter os meios de comunicação descritos por Andriof e Waddock (2002), pois a imprensa, por meio da sua atuação, contribui para o referido controle ao demonstrar como os recursos públicos estão sendo utilizados.

Por fim, Gomes et al. (2010) mencionam, ainda, a categoria "formador de agenda", que recebe essa denominação por se referir aos atores cuja influência decorre do poder de definir a agenda que o governo deve cumprir. Deve-se salientar que o trabalho de Gomes et al. (2010) ressalta o papel dos atores na formulação e na implementação de políticas públicas, o que constitui tema que continua a integrar a agenda de pesquisa, tendo em vista que uma das questões emergentes é a análise da influência que os atores podem exercer na tomada de decisões do governo. Isso porque "muito pouco se sabe sobre a importância das influências dos Stakeholders no desempenho do governo local" (Gomes, Osborne \& Guarnieri, 2020, p. 464).

Olander (2007) propôs um modelo que parece ser uma síntese parcial, compartilhando algumas premissas de Mitchel et al. (1997) e de Savage et al. (1991), pois utiliza o aspecto poder de influenciar a organização, atribuindo graus de intensidade (baixa, média e alta), porém também leva em consideração o nível de interesse do ator nas atividades da organização. Assim como o modelo de Savage et al. (1991), o referido nível pressupõe que o Stakeholder pode cooperar ou ameaçar a organização, por isso, de acordo com o nível de interesse, o ator pode ser considerado como opositor, neutro ou apoiador. A classificação final do ator decorre do seu enquadramento em uma matriz, na qual, no eixo vertical, estão os graus de intensidade de poder, e, no eixo horizontal, estão os níveis de interesse.

Harrison e Bosse (2013) propõem um modelo de análise que considera o montante de valor alocado para os Stakeholders em função de seu poder e da sua importância estratégica. Assim, o Stakeholder terá prioridade máxima caso possua alto poder e alta importância estratégica. O ator terá prioridade alta se 
possuir baixo poder e alta importância estratégica. $\mathrm{O}$ ator terá prioridade moderada caso detenha alto poder e baixa importância estratégica. O Stakeholder terá prioridade baixa caso possua baixo poder e baixa importância estratégica (Rudzevicius, Boaventura, Mascena \& Sarturi, 2018).

Deve-se salientar que Harrison e Bosse (2013) abordam a questão da criação e alocação de valor para Stakeholders, a qual continua a integrar a agenda de pesquisa. Isso porque um dos desafios postos à Teoria de Stakeholders é o de contabilizar a geração de valor não apenas para os acionistas, mas também para os outros Stakeholders, pois é necessário compreender o que conta para o bom desempenho de um negócio de modo a contabilizar não apenas a geração de valor para os investidores (Freeman, 2017).

Assim, é preciso encontrar novas métricas, além do lucro, para medir o referido desempenho, de modo a captar o valor criado para clientes, empregados e outros atores. Nesse contexto, Wood, Mitchell, Agle e Bryan (2018) sustentam que estudos futuros devem investigar como obter melhor desempenho, maior criação de valor e equidade para todas as partes interessadas, a fim de incluir todos os atores e oportunizar benefícios para eles de forma proporcional à contribuição que deram à organização.

No mesmo sentido, Hatherly, R. Mitchell, J. Mitchell e Lee (2020) sugerem que é necessário ocorrer mudanças nos métodos contábeis utilizados para distribuir os lucros, de modo a torná-los mais orientados para outras partes interessadas, além dos acionistas. Assim, os autores defendem que sejam pesquisadas novas métricas, como, por exemplo, um conceito de dividendos para Stakeholders. Enfim, os autores sugerem que é preciso conceber formas de contabilizar e reconhecer as contribuições decorrentes das ações das diversas partes interessadas.

Outro exemplo é o trabalho de Kujala, Lehtimäki e Freeman (2019), o qual sustenta que, embora a literatura considere que as organizações podem criar valor para os atores por meio das suas relações com eles, é preciso avançar no conhecimento sobre como o valor é criado em tais relacionamentos.

Nesse contexto, os autores propõem um modelo que visa contribuir para o entendimento das maneiras pelas quais as organizações criam valor. Trata-se do modelo denominado de Stakeholder Value Creation (SVC), segundo o qual a criação de valor ocorrerá em relacionamentos que possuam os seguintes atributos: interesses em comum, capacidade de colaboração e confiança entre as partes. Desse modo, a SVC é vista como a "capacidade de uma organização criar relacionamentos duradouros com seus Stakeholders" (Kujala, Lehtimäki \& Freeman, 2019, p. 130) em função da convergência de interesses, da capacidade de colaboração e da confiança dos Stakeholders. Por fim, demonstra-se, por meio da Tabela 2, a evolução dos referidos modelos. 
Tabela 2 - Evolução dos modelos de análise de Stakeholder

\begin{tabular}{cl}
\hline Década de 1980 & Modelos de análise de Stakeholders \\
\hline Atores podem ser internos e externos (Freeman, 1984). \\
\hline Década de 1990 - Parte I & $\begin{array}{l}\text { Atores podem cooperar ou ameaçar a organização (Savage et al., 1991), } \\
\text { bem como podem ser primários (ou seja, associados diretamente à } \\
\text { sobrevivência da organização) ou secundários (ou seja, não são essenciais } \\
\text { para sua sobrevivência) (Clarkson, 1995). }\end{array}$ \\
\hline
\end{tabular}

Atores podem ser classificados de acordo com o poder de influenciar a organização, a legitimidade do relacionamento com a organização e a urgência no atendimento do seu interesse (Mitchell et al., 1997). A

Década de 1990 - Parte II identificação desses atributos permite estabelecer o nível de prioridade (Friedman \& Miles, 2006) ou graus de intensidade (Schepper et al., 2014). Além disso, a classificação deve considerar os aspectos descritivo, normativo e instrumental (Donaldson \& Preston, 1995). A estratégia de influência dos atores inclui o uso dos seus recursos (Frooman, 1999).

Década de 2000

Atores podem ser classificados de acordo com o papel que exercem na formulação e na implementação de políticas públicas (Gomes et al., 2010), em função do nível de interesse dele nas atividades da organização (Olander, 2007), em virtude da relevância na rede de relações da organização (Reed et al., 2009), do nível de poder, envolvimento e influência no processo decisório (Curzon, 2009), conforme o valor alocado a ele (Harrison \& Bosse, 2013) ou do modo como ocorre o relacionamento com a organização (Carroll \& Buchholtz, 2011).

Fonte: Elaborada pelos autores.

Portanto, percebe-se que, assim como ocorreu com a evolução da definição de Stakeholder, os modelos de classificação evoluíram de uma caracterização mais genérica (internos e externos) para outras que abordam questões específicas, como o papel da formulação de políticas públicas e o valor alocado para os atores. Além disso, novos modelos, por vezes, buscam complementar ou aperfeiçoar modelos antigos como ocorreu, por exemplo, com os modelos de Schepper et al. (2014) e Mitchell et al. (1997) ou, ainda, entre Carroll e Buchholtz (2011) e Clarkson (1995).

\section{Método}

Trata-se de uma pesquisa descritiva, pois tem o objetivo de demonstrar características da produção acadêmica sobre Stakeholders. Para tanto, foram adotadas as técnicas de pesquisa bibliográfica e bibliométrica. A análise bibliográfica foi utilizada por permitir evidenciar aspectos da produção científica sobre um determinado tema (Ferreira, Gomes, Lima \& Mello, 2019). Também foi utilizado o estudo bibliométrico, o qual possibilita a verificação de produção e disseminação do conhecimento científico (Araújo, 2006). 
Isso porque os resultados foram examinados tendo em vista as leis clássicas da bibliometria, ou seja, as leis de Lokta, Bradford e Zipf. A Lei de Lotka fornece uma relação entre autores e artigos (Hood \& Wilson, 2001) e visa aferir a produtividade de autores. A referida lei surgiu a partir de um estudo sobre a produtividade dos cientistas, no qual descobriu-se que a maioria da literatura científica é produzida por um pequeno número de autores (Araújo, 2006).

Enquanto a Lei de Lotka tem por objeto os autores, a Lei de Bradford volta-se para os periódicos, pois objetiva analisar a produtividade dessas revistas científicas. A Lei de Bradford aborda a questão da escassez de artigos sobre um determinado assunto em tais periódicos. Isso porque Bradford percebeu, após analisar uma coleção de periódicos, que existe um pequeno núcleo de periódicos que mais publica sobre determinado assunto (Hood \& Wilson, 2001).

Essa conclusão resulta da análise de um conjunto de periódicos em ordem de produtividade decrescente. Dessa forma, é possível identificar três zonas, cada uma contendo um terço do total de artigos, sendo que a primeira delas caracteriza-se por conter um pequeno número de periódicos altamente produtivos, ou seja, a Lei de Bradford prega que "se dispormos periódicos em ordem decrescente de produtividade de artigos sobre um determinado tema, pode-se distinguir um núcleo de periódicos mais particularmente devotados ao tema" (Araújo, 2006, p. 15).

A Lei de Zipf concentra-se nas palavras, pois busca identificar a frequência ou ocorrência delas (Hood \& Wilson, 2001). De acordo com Araújo (2006), Zipf concluiu que existe uma regularidade no uso das palavras e que um pequeno número de palavras é usado de forma mais frequente em um documento. De acordo com Ferreira et al. (2019), uma forma de verificar a aplicação da Lei de Zipf é a utilização de uma nuvem de palavras, a qual permite identificar as palavras mais recorrentes em um conjunto de termos, a partir da análise dos termos utilizados nas palavras-chave dos artigos que compõem a amostra pesquisada.

Nesse contexto, realizou-se uma revisão de literatura, na qual foram selecionados trabalhos publicados, entre 2014 e 2019, em periódicos científicos nacionais, com classificação no Qualis/CAPES de A2 a B2 em Administração Pública e de Empresas, Ciências Contábeis e Turismo, o que totalizou 92 revistas. Algumas revistas possuem versão on-line e impressa. Nesse caso, foi contabilizada apenas a versão on-line.

A feitura deste recorte se deu em razão do fato de que tais periódicos representam a produção acadêmica de alta qualidade publicada no país no período recente sobre Administração e as áreas afins, acima mencionadas, tendo em vista que a análise dos artigos produzidos nos últimos cinco anos é um indicador do estado da arte sobre determinado tema, sendo, inclusive, utilizado como filtro de pesquisa no portal de periódicos da CAPES. No mesmo sentido, uma recente revisão de literatura sobre tema organizacional, publicada em um dos periódicos que integra a amostra dessa pesquisa, recomenda que o foco para novas pesquisas esteja nas produções dos últimos cinco anos (Fraga, Gemelli \& Oliveira, 2019).

A seleção dos artigos foi realizada por meio da utilização das palavras-chave "Stakeholder", "Stakeholders" ou "partes interessadas". Os termos usados na busca foram escolhidos por serem os mais 
utilizados em artigos científicos que utilizaram a teoria. Com base nos critérios de pesquisa citados, foram identificados 271 artigos que contêm as referidas palavras nos seus títulos, resumos e/ou palavras-chave. Em seguida, foi feita a leitura dos artigos com a finalidade de verificar se os estudos encontrados utilizam a Teoria dos Stakeholders como referencial teórico ou se apenas citam os termos no corpo do texto, sem necessariamente usar a teoria para fundamentar a análise. Deste modo, foi identificada uma amostra de 89 artigos que efetivamente aplicam a teoria na análise de organizações.

Os referidos artigos foram classificados por meio das seguintes categorias de análise: (1) nome do periódico; (2) enquadramento do estudo; (3) quantidade de autores; (4) instituições de origem dos autores; (5) autores que mais publicaram no período; (6) objetivos dos estudos; (7) natureza do estudo; (8) o ramo de atuação das empresas pesquisadas; (9) instrumentos de coleta de dados utilizados; (10) técnicas de análises de dados aplicadas; (11) a definição de Stakeholder utilizada; e (12) modelo de análise de Stakeholder usado. As categorias de análise 8 a 10 foram utilizadas apenas para analisar os artigos teóricoempíricos, uma vez que tal exame não era possível de ser aplicado em artigos com enquadramento teórico apenas.

O enquadramento dos estudos levou em consideração as seguintes abordagens: teórica, teóricoempírica e empírica. A abordagem teórica discute conceitos, proposições, identificação de variáveis ou construção de modelos, porém não há a realização de testes para verificar a aplicação do modelo. Na abordagem teórico-empírica, os estudos partem de um quadro teórico de referência e tentam refutá-lo ou corroborá-lo. Por fim, a abordagem empírica concentra-se na observação e análise dos dados, sem relacioná-los a um referencial teórico específico.

Em relação aos objetivos do estudo, foram considerados os seguintes tipos: (1) estudo de antecedentes e consequentes; (2) compreensão de um fenômeno; (3) aprofundamento teórico; e (4) revisão de literatura. Foram considerados estudo de antecedentes e consequentes os estudos que formularam e testaram hipóteses para compreender um determinado fenômeno. Por outro lado, foram tidos como compreensão de um fenômeno os estudos que buscaram tal compreensão sem a formulação e teste de hipóteses. Foram classificados como aprofundamento teórico os estudos que visaram compreender a evolução de um determinado conceito ou outro aspecto teórico de um corpo do conhecimento. Por fim, foram considerados revisão de literatura os estudos que tiveram a finalidade de analisar o perfil da produção acadêmica sobre um determinado corpo do conhecimento. Em relação à definição e ao modelo de análise de Stakeholder utilizados, foram levados em conta aqueles suscitados no referencial teórico.

Deve-se ressaltar que essas categorias de análise estão, parcialmente, baseadas em Cintra, Amâncio-Vieira, Suzuki e Costa (2014), os quais realizaram uma investigação de artigos sobre Stakeholders publicados em periódicos nacionais antes de 2014. Isso porque identificaram periódicos e autores que mais publicam sobre o tema, as instituições de ensino às quais os autores estão vinculados e as definições de Stakeholders mais citadas. 
Na ocasião, os autores sugeriram, como agenda de pesquisa futura, a realização de uma revisão de literatura que abordasse aspectos qualitativos e metodológicos utilizados, o que é efetuado no presente trabalho. Assim, a presente pesquisa não apenas atualiza os elementos identificados por Cintra et al. (2014), como também incorpora novos aspectos qualitativos e metodológicos (enquadramento, objetivos e natureza do estudo, instrumentos de coleta de dados, técnicas de análise de dados e modelo de análise de Stakeholder).

\section{Análise dos resultados}

Tendo em vista que esse estudo objetiva contribuir para pesquisas futuras que utilizem a Teoria dos Stakeholders como referencial teórico, são identificados, nessa seção, os principais periódicos e autores que publicam sobre o tema, os métodos utilizados para coletar e analisar os dados, bem como as demais categorias de análise citadas anteriormente.

Nesse sentido, conforme demonstra a Figura 1, verificou-se que a RBGN, a RAUFSM e a RIAE são os periódicos que mais publicaram artigos sobre o tema. Em função da limitação de espaço, são demonstrados apenas os periódicos que publicaram três ou mais artigos.

Figura 1 - Artigos que utilizaram a Teoria dos Stakeholders por periódicos

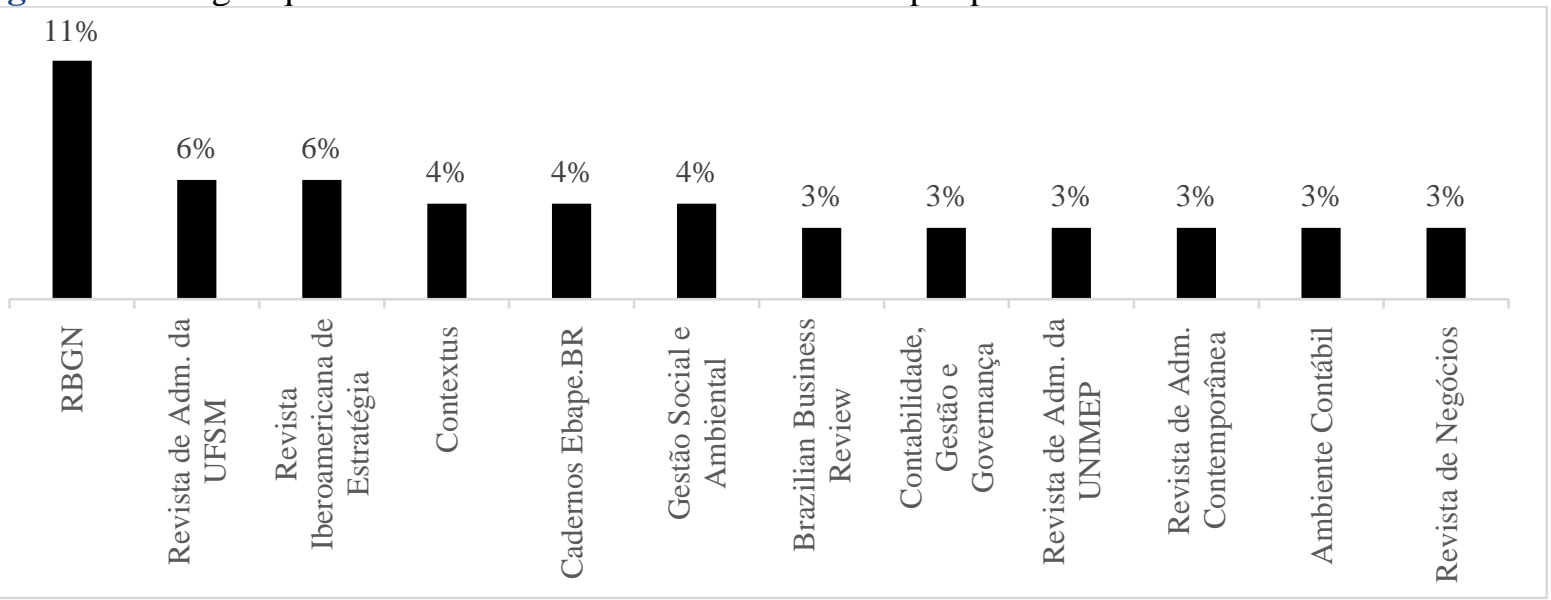

Fonte: Elaborada pelos autores.

A informação de que trata a Figura 1 pode ser utilizada para a verificação da aplicação da Lei de Bradford. Para tanto, os periódicos foram dispostos em ordem decrescente de produtividade de artigos e identificadas as três zonas mencionadas anteriormente. A confirmação da aplicação da referida lei ocorre se a primeira zona contiver um pequeno número de periódicos altamente produtivos; a segunda, um número maior de periódicos menos produtivos; e a terceira, uma grande quantidade de periódicos, porém tais periódicos devem apresentar uma menor produtividade quando comparados aos das outras zonas (Araújo, 2006). 
Assim, os 89 artigos que compõem a amostra foram divididos em três zonas, de modo que cada zona contenha cerca de 30 artigos. O resultado é demonstrado na Tabela 3, a qual parece confirmar a referida lei, haja vista que, apesar da pulverização de periódicos, é possível observar uma concentração de artigos em um pequeno número de periódicos, ou seja, é possível identificar um núcleo de periódicos mais devotos ao tema, denominado de core daquele assunto (Araújo, 2006), os quais parecem ser os de maior relevância naquela área (Guedes \& Borschiver, 2005). Na Tabela 3, esse núcleo corresponde à zona A (concentração ou core).

Tabela 3 - Lei de Bradford

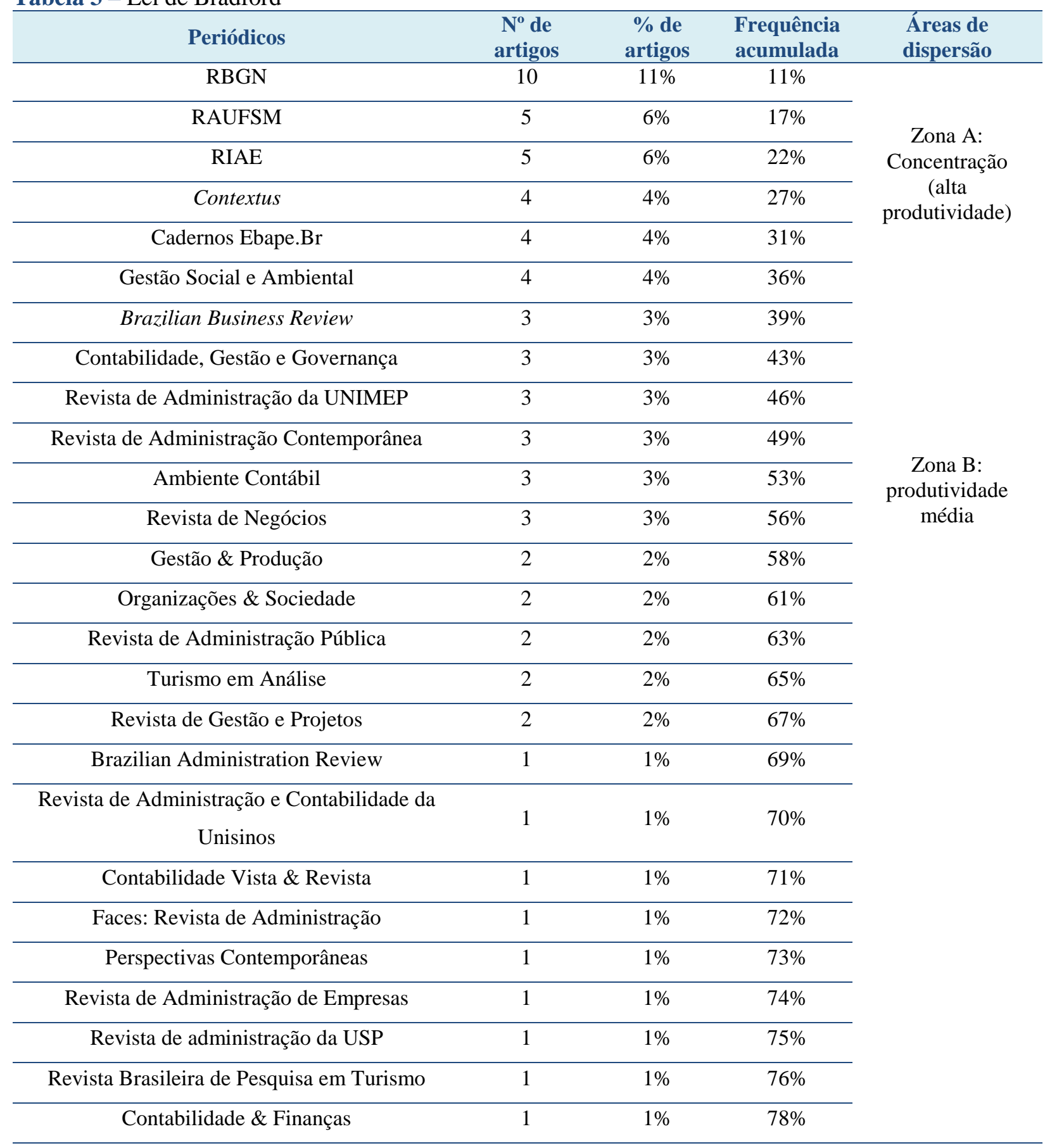




\begin{tabular}{|c|c|c|c|c|}
\hline Periódicos & $\begin{array}{c}\mathrm{N}^{\circ} \text { de } \\
\text { artigos }\end{array}$ & $\begin{array}{c}\% \text { de } \\
\text { artigos }\end{array}$ & $\begin{array}{l}\text { Frequência } \\
\text { acumulada }\end{array}$ & $\begin{array}{l}\text { Áreas de } \\
\text { dispersão }\end{array}$ \\
\hline Revista de Ciências da Administração & 1 & $1 \%$ & $79 \%$ & \multirow{20}{*}{$\begin{array}{c}\text { Zona } \mathrm{C} \text { : } \\
\text { baixa } \\
\text { produtividade }\end{array}$} \\
\hline Revista de Ciências Administrativas & 1 & $1 \%$ & $80 \%$ & \\
\hline Organizações em Contexto & 1 & $1 \%$ & $81 \%$ & \\
\hline Revista Portuguesa e Brasileira de Gestão & 1 & $1 \%$ & $82 \%$ & \\
\hline Revista Pretexto & 1 & $1 \%$ & $83 \%$ & \\
\hline Universo Contábil & 1 & $1 \%$ & $84 \%$ & \\
\hline Sociedade, Contabilidade e Gestão & 1 & $1 \%$ & $85 \%$ & \\
\hline $\begin{array}{l}\text { Revista Brasileira de Gestão e } \\
\text { Desenvolvimento Regional }\end{array}$ & 1 & $1 \%$ & $87 \%$ & \\
\hline Revista Brasileira de Gestão Urbana & 1 & $1 \%$ & $88 \%$ & \\
\hline Revista Catarinense da Ciência Contábil & 1 & $1 \%$ & $89 \%$ & \\
\hline Revista de Gestão Ambiental e Sustentabilidade & 1 & $1 \%$ & $90 \%$ & \\
\hline Revista em Agronegócios e Meio Ambiente & 1 & $1 \%$ & $91 \%$ & \\
\hline Revista de Administração Mackenzie & 1 & $1 \%$ & $92 \%$ & \\
\hline Revista Eletrônica de Administração & 1 & $1 \%$ & $93 \%$ & \\
\hline Revista Alcance & 1 & $1 \%$ & $94 \%$ & \\
\hline Revista Brasileira de Estratégia & 1 & $1 \%$ & $96 \%$ & \\
\hline Revista Desenvolvimento em Questão & 1 & $1 \%$ & $97 \%$ & \\
\hline Revista do Serviço Público & 1 & $1 \%$ & $98 \%$ & \\
\hline Revista Eletrônica de Estratégia e Negócios & 1 & $1 \%$ & $99 \%$ & \\
\hline Administração Pública e Gestão Social & 1 & $1 \%$ & $100 \%$ & \\
\hline
\end{tabular}

Fonte: Elaborada pelos autores.

Em relação ao enquadramento do estudo, a maioria dos estudos pode ser classificada como teórico-empírico (90\%). Corroborando esse resultado, Takahashi e Semprebom (2013), ao realizarem uma análise bibliométrica de 2.895 artigos publicados em periódicos e eventos científicos nacionais sobre Administração, encontraram que 93\% deles utilizavam uma abordagem teórico-empírica.

Em relação à quantidade de autores, a Figura 2 demonstra que, embora tenham sido encontrados mais de 200 autores na amostra pesquisada, é rara a publicação de artigos com apenas um autor. Prevalecem os artigos produzidos por dois ou mais autores. Nesse sentido, parece estar ocorrendo uma consolidação de grupos de pesquisa que estudam a Teoria dos Stakeholders. 
Figura 2 - Quantidade de autores

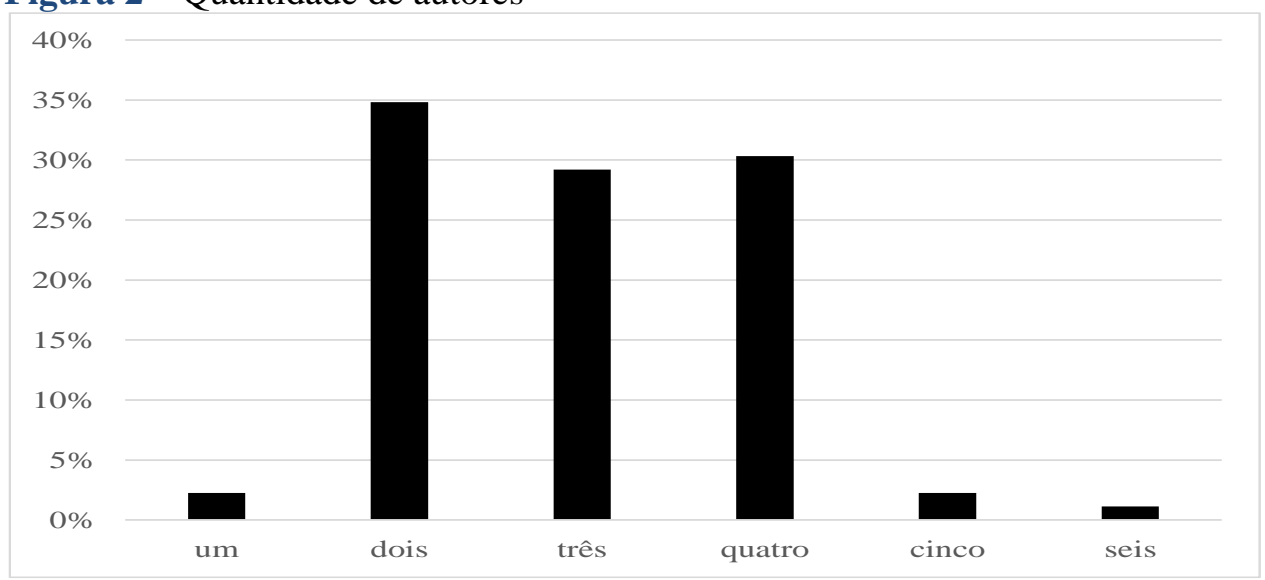

Fonte: Elaborada pelos autores.

Em relação às instituições de origem dos autores, deve-se ressaltar que foi considerado na contagem apenas um artigo por universidade, ainda que o artigo tenha sido publicado por mais de um autor pertence àquela universidade. Por exemplo, em Vieira e Gomes (2014), embora ambos sejam professores da Universidade de Brasília (UnB), foi associado apenas um artigo à UnB.

$\mathrm{Na}$ amostra foi encontrada uma grande pulverização de autores e universidades a eles associadas, de modo que foi necessário restringir o número de universidades evidenciadas na figura abaixo. Por isso, na Figura 3 é apresentada a origem dos pesquisadores cujas instituições atingiram um percentual mínimo de 4\% dos artigos selecionados. As Universidades de São Paulo e a Nove de Julho são as instituições com maior quantidade de publicações.

Figura 3 - Instituição de origem dos autores

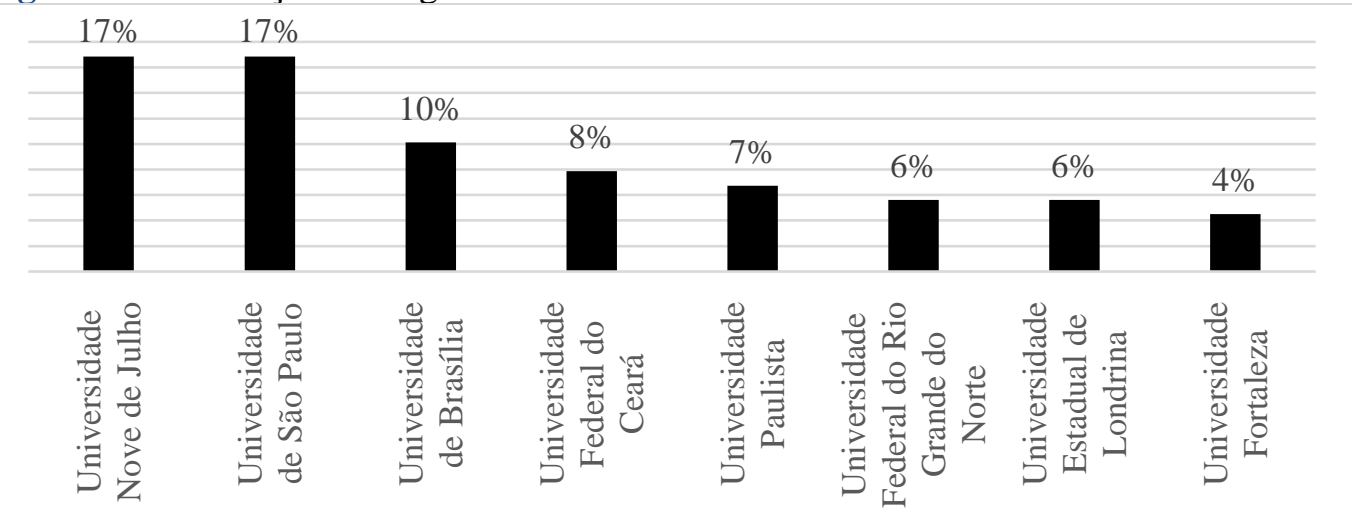

Fonte: Elaborada pelos autores

Observa-se uma relativa concentração da produção nas universidades paulistas (USP, UNINOVE e UNIP), pois, embora tenham sido identificados autores pertencentes a 62 universidades, essas 3 universidades paulistas respondem por cerca de $41 \%$ dos artigos da amostra. A explicação desse fenômeno requer a análise dos autores, o que é feito na Tabela 4, a qual demonstra que os três autores que mais 
publicaram sobre o tema pertencem à UNINOVE e à USP. Deve-se ressaltar que os autores que publicaram 2 ou menos artigos não foram relacionados.

Tabela 4 - Autores que mais publicaram no período selecionado

\begin{tabular}{lc}
\multicolumn{1}{c}{ Autores } & $\mathbf{N}^{\circ}$ de artigos \\
\hline Benny Kramer Costa - Universidade Nove de Julho (UNINOVE) & 8 \\
\hline João Maurício Gama Boaventura - Universidade de São Paulo (USP) & 7 \\
\hline Henrique César Melo Ribeiro - Universidade Nove de Julho (UNINOVE) & 5 \\
\hline Saulo Fabiano Amâncio-Vieira - Universidade Estadual de Londrina (UEL) & 5 \\
\hline Keysa Manuela Cunha de Mascena - Universidade de São Paulo (USP) & 5 \\
\hline Ricardo Corrêa Gomes - Universidade de Brasília (UnB) & 4 \\
\hline Roberto Bazanini (UNIP) & 3 \\
\hline Mônica Cavalcanti Sá de Abreu - Universidade Federal do Ceará (UFC) & 3 \\
\hline Greici Sarturi (UFSM) & 3 \\
\hline
\end{tabular}

Fonte: Elaborada pelos autores.

A análise da informação acerca das publicações por autor permite verificar a ocorrência, ou não, da Lei de Lotka, segundo a qual uma larga proporção da literatura científica é produzida por um pequeno número de autores (Araújo, 2006). Nesse sentido, a referida lei parece ter como premissa o fato de que alguns pesquisadores publicam muito mais que uma grande quantidade de autores os quais produzem pouco.

Voos (1974) explica que Lotka descobriu que podia prever o número de artigos que um autor escreveria desde que soubesse quantos autores escreveram apenas um artigo durante um determinado período de tempo. Nesse sentido, foi estabelecido um fator para prever o número de artigos em uma área, o qual seria $1 / \mathrm{n}^{2}$ do número de autores (n) que escreveram apenas um artigo. Essa relação entre o número de autores e de artigos publicados estabeleceu os fundamentos da denominada Lei do Inverso do Quadrado (Urbizagastegui, 2008).

Dessa forma, o número de autores que escrevem dois artigos seria igual a 1/4 do número de autores que escreveram um, e o número dos que escreveram três artigos seria igual a 1/9 do número dos que escreveram um, e assim sucessivamente (Guedes \& Borschiver, 2005). Outra forma de explicar a referida lei, que é citada por Voos (1974), é a seguinte: se 100 autores escreveram um artigo, apenas 25 escreveriam dois artigos e apenas 11 escreveriam três artigos. Assim, procedeu-se a verificação da aplicação da referida lei conforme demonstrado na Tabela 5 . 
Tabela 5 - Lei do Inverso do Quadrado

\begin{tabular}{ccc}
\hline $\mathbf{N}^{\mathbf{o}}$ de artigos publicados & Autores & Qte. de autores conforme Lei do Quadrado Inverso \\
\hline 1 & 194 & 194 \\
\hline 2 & 14 & 49 \\
\hline 3 & 3 & 22 \\
\hline 4 & 1 & 12 \\
\hline 5 & 3 & 8 \\
\hline 6 & 0 & 5 \\
\hline 7 & 1 & 4 \\
\hline 8 & 1 & 3
\end{tabular}

Fonte: Elaborada pelos autores.

Além disso, segundo a Lei de Lotka, a proporção dos autores que fazem uma única contribuição é de cerca de 60\% (Urbizagastegui, 2008). Deve-se ressaltar que esse percentual é usado como referência na verificação da aplicação da Lei de Lotka, inclusive, é denominado de padrão Lotka em alguns trabalhos, como o de Voese e Mello (2013). Conforme demonstrado na Tabela 6, há uma pulverização na distribuição autoral que pode ser evidenciada, por exemplo, pelo percentual de autores que produziram um único artigo $(89,4 \%)$. Contudo, o percentual encontrado é superior ao parâmetro de referência (60\%).

Tabela 6 - Produtividade dos autores

\begin{tabular}{ccc}
\hline $\mathbf{N}^{\mathbf{0}}$ de artigos publicados & Autores & \% dos autores \\
\hline 8 & 1 & $0,5 \%$ \\
\hline 7 & 1 & $0,5 \%$ \\
\hline 6 & 0 & $0 \%$ \\
\hline 5 & 3 & $1,4 \%$ \\
\hline 4 & 1 & $0,5 \%$ \\
\hline 3 & 3 & $1,4 \%$ \\
\hline 2 & 14 & $6,5 \%$ \\
\hline 1 & 194 & $89,4 \%$ \\
\hline Total & $\mathbf{2 1 7}$ & $\mathbf{1 0 0 \%}$
\end{tabular}

Fonte: Elaborada pelos autores. 
Portanto, embora exista uma grande quantidade de autores que publicou um único artigo, não foi possível confirmar a aplicação da Lei do Inverso do Quadrado e tampouco do parâmetro relativo à proporção dos autores que fazem uma única contribuição. Nesse contexto, entende-se que não foi possível confirmar a validade de Lei de Lotka.

No que tange aos objetivos dos estudos, a compreensão de um fenômeno foi o objetivo mais recorrente, sendo citado em $73 \%$ dos artigos pesquisados, seguido por aprofundamento teórico (12\%), estudo de antecedentes e consequentes ( $8 \%$ ) e revisão de literatura (7\%).

Deve-se ressaltar que os objetivos descritos nos artigos foram analisados de modo a verificar se abordam questões convergentes com a agenda de pesquisa ou temas sobre os quais a Teoria de Stakeholder precisa avançar. Essa agenda de pesquisa inclui a análise da geração de valor, o seu significado para os diferentes Stakeholders e a sua distribuição entre tais atores (Parmar et al., 2010; Harrison, Freeman \& Abreu, 2015). Nesse sentido, deve-se ressaltar que alguns artigos da amostra são convergentes com essa agenda, como é o caso do trabalho de Rudzevicius et al. (2018), os quais analisaram a alocação de valor para os Stakeholders no setor financeiro.

No que tange à natureza do estudo, a pesquisa qualitativa é a mais recorrente, presente em $61 \%$ dos artigos pesquisados. Esse resultado é harmônico com o encontrado por Pavão e Rosseto (2015), os quais afirmam que há predominância de pesquisas qualitativas em estudos sobre a Teoria dos Stakeholders. A natureza multimétodo e a quantitativa representaram, respectivamente, cerca de $25 \%$ e $14 \%$ dos estudos selecionados.

A pesquisa de natureza qualitativa parece predominar, pois vários estudos da amostra visam identificar os Stakeholders, classificá-los e verificar a forma de atuação desses atores. Para tanto, são realizadas entrevistas com atores envolvidos com o fenômeno que se quer compreender. Esse é o caso, por exemplo, do artigo elaborado por Pagnussatt, Petrini, Silveira e Santos (2018), que analisaram quais são e como atuam os atores envolvidos em Pequenas Centrais Hidrelétricas. Para tanto, entrevistaram, por exemplo, representantes da Secretaria de Minas e Energia do Rio Grande do Sul. Isso é convergente ao fato de que os pesquisadores qualitativos "estudam as coisas em seus cenários naturais, tentando entender os fenômenos em termos dos significados que as pessoas a eles conferem" (Godoy, 2013, p. 36).

No tocante ao segmento da economia em que a empresa pesquisada atua, nota-se que os segmentos turismo, esportivo e educacional são os mais estudados. Deve ser esclarecido que, em alguns dos estudos, foram analisadas empresas pertencentes a dois ou três segmentos setoriais, como é o caso de Cabral, Fernandes e Ribeiro (2016), que analisaram empresas que atuam no segmento hospitalar, esportivo e de saneamento. Neste caso, cada ramo de atuação foi contabilizado como uma unidade. Informa-se, ainda, que foram classificados na categoria "diversos" os estudos, como o Oliveira et al (2014), que analisaram empresas pertencentes a mais de três segmentos. Vale ressaltar que, na amostra, foi encontrada uma pulverização de segmentos de atuação, de modo que a Figura 4 demonstra apenas os segmentos citados em dois ou mais artigos. 
Figura 4 - Ramo de atuação das empresas pesquisadas

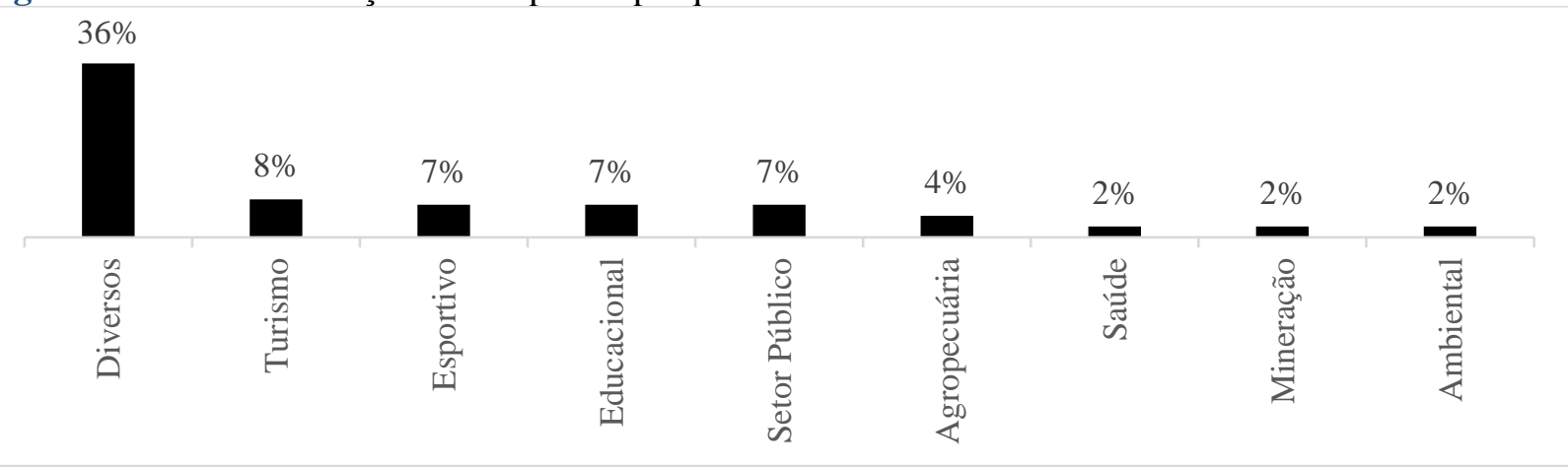

Fonte: Elaborada pelos autores.

A predominância do estudo de diversos setores, bem como a amplitude dos setores demonstrados na Figura 4, corroboram com o fato de que a Teoria dos Stakeholders está relacionada a diferentes áreas do conhecimento, o que comprova a sua relevância para as organizações em geral (Ribeiro \& Costa, 2017b). A Figura 4 demonstra, ainda, que, embora existam modelos de análise voltados para o estudo de organizações públicas, como é o caso do proposto por Gomes et al. (2010), há uma pequena quantidade de estudos sobre o setor público.

Em relação aos instrumentos de coleta de dados, tem-se que a pesquisa documental (inclui a pesquisa bibliográfica), com $58 \%$, foi a mais utilizada. A entrevista vem na sequência, com $44 \%$, e o questionário, com 18\%. A observação direta, as observações participantes e não participantes, e o grupo focal foram as demais formas de coleta citadas. O somatório demonstrado é superior ao percentual de 100\%, pois alguns estudos utilizam mais de um instrumento de coleta, como é o caso de Miragaia, Ferreira e Ratten (2017), que utilizaram questionário e entrevista. Além disso, a presença da entrevista e da observação direta entre os principais instrumentos de coleta parece estar relacionada com o predomínio da natureza qualitativa entre os estudos que compõem a amostra dessa pesquisa, tendo em vista que tais instrumentos são típicos de estudos qualitativos (Godoy, 2013).

Em relação às técnicas de análise de dados, a análise de conteúdo foi a mais utilizada (64\%), seguida pela estatística descritiva (23\%) e regressões múltiplas (7\%). Na Figura 5, não são citadas as técnicas que apresentaram baixa frequência (técnicas utilizadas em apenas um único artigo), em virtude da limitação de espaço e da baixa representatividade. 
Figura 5 - Técnicas de análise de dados mais utilizadas

$64 \%$
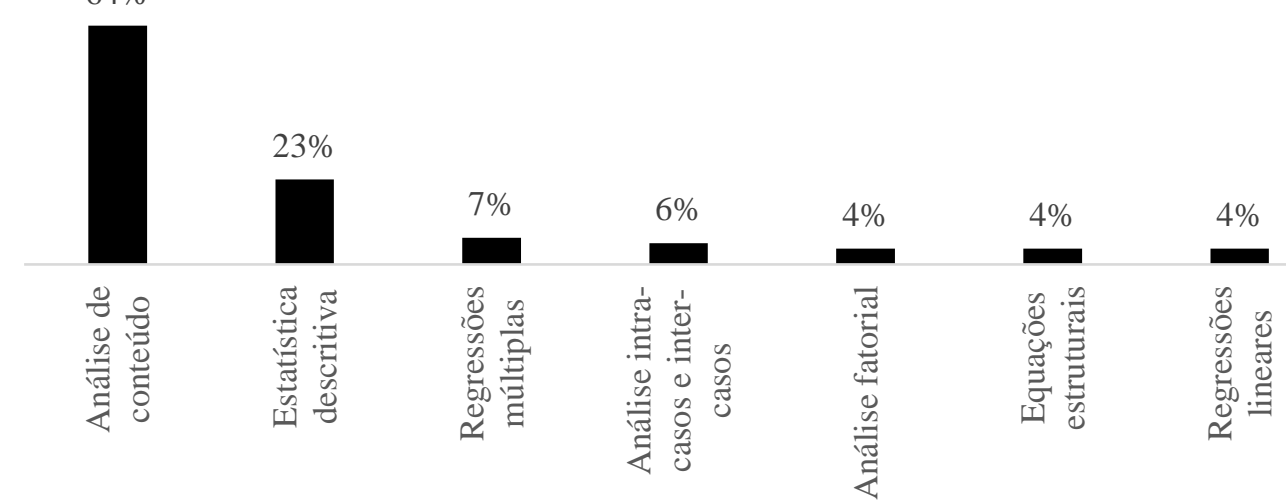

$3 \%$
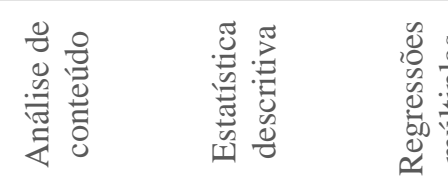

Fonte: Elaborada pelos autores.

A definição de Stakeholder mais usada é a de Freeman (1984), conforme demonstra a Figura 6. Esse resultado é consonante com o fato de que os estudos sobre a Teoria dos Stakeholders, realizados durante o Século XX, utilizaram a referida definição como fundamentação analítica (Pavão \& Rosseto, 2015). Deve-se ressaltar que $17 \%$ dos artigos publicados não informaram a definição utilizada. Por outro lado, alguns estudos utilizaram mais de uma definição e, por isso, o somatório ultrapassa 100\%. Além disso, em função da baixa representatividade, não são citadas as definições identificadas em apenas um artigo.

O predomínio da definição de Freeman (1984) pode estar relacionado com a sua amplitude e generalidade, de modo que favorece a aderência aos diversos setores da economia. Além disso, uma definição ampla parece ser convergente com o fato de que a Teoria dos Stakeholders possui um enfoque compreensivo, que visa englobar todas as partes interessadas, e não apenas determinados grupos, como fazem outras teorias da Administração (Harrison et al., 2015). Nesse sentido, os autores exemplificam que as Teorias sobre Recursos Humanos tendem a focar em um subgrupo de Stakeholders, os empregados.

Figura 6 - Definição de Stakeholder

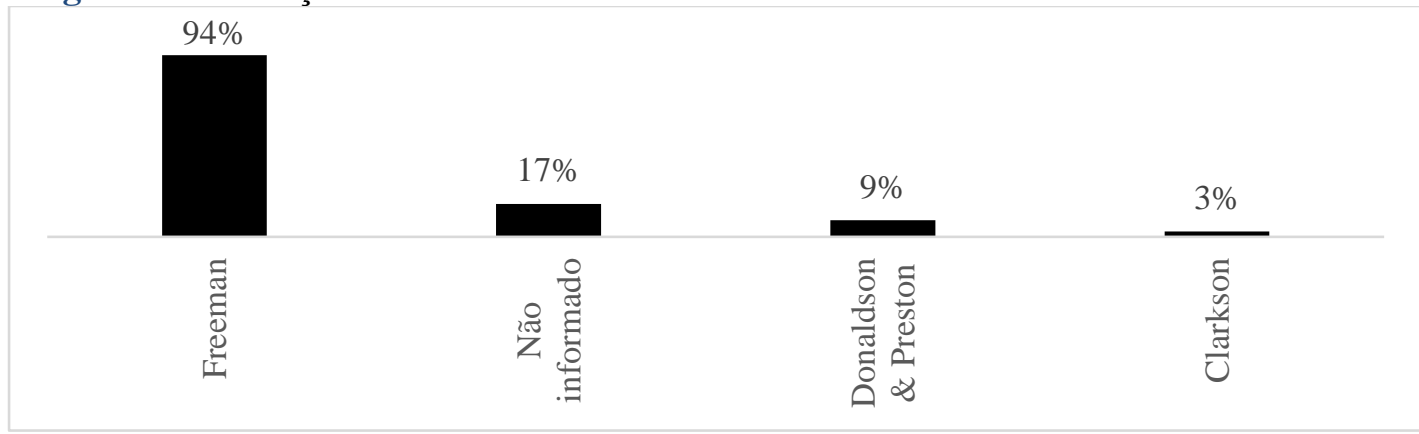

Fonte: Elaborada pelos autores.

Em relação ao modelo de análise, foi identificado que o de Mitchell et al. (1997) é o mais utilizado. Deve-se ressaltar que mais da metade dos trabalhos não informou o modelo de análise escolhido. Além disso, alguns estudos usaram mais de um modelo e, por isso, o somatório ultrapassa $100 \%$. 
Figura 7 - Modelo de análise de Stakeholder

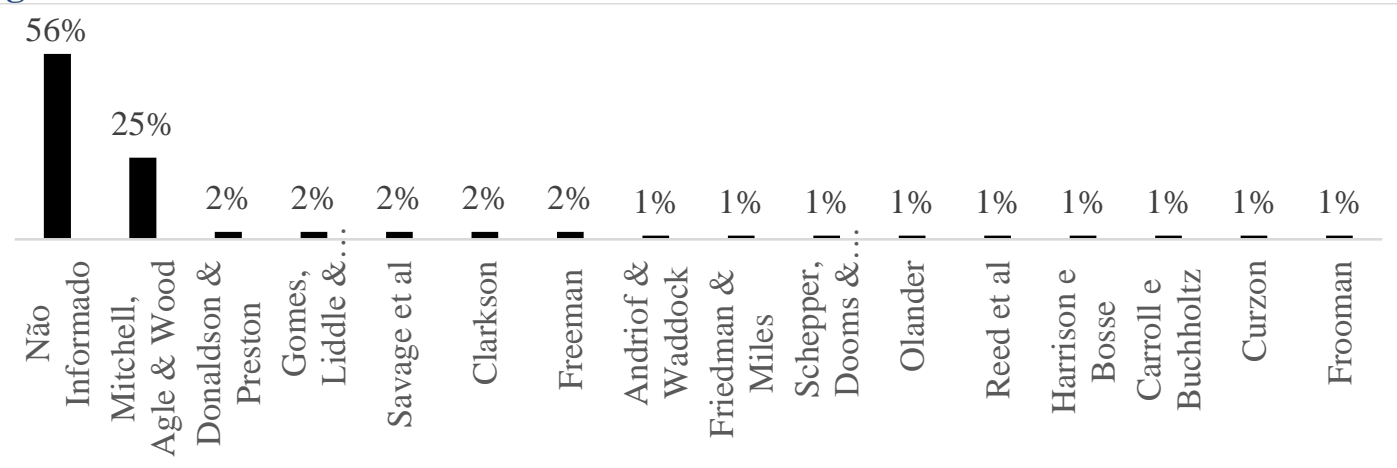

Fonte: Elaborada pelos autores.

A análise das Figuras 6 e 7 demonstra que, com exceção da definição proposta por Gomes \& Gomes (2015) e do modelo de Gomes et al. (2010), as definições e modelos utilizados são de autores estrangeiros.

Por fim, foi verificada a confirmação da Lei de Zipf, a qual aborda a frequência de palavras em um determinado texto (Araújo, 2006) e prevê que existem palavras que se repetem muito mais vezes que outras, possuindo alta frequência de ocorrência (Guedes \& Borschiver, 2005). Nesse sentido, foram analisadas as palavras-chave dos artigos. Deve-se ressaltar que essa forma de verificar a frequência das palavras foi utilizada em estudo bibliométrico recente (Ferreira et al., 2019).

De acordo com Guedes e Borschiver (2005), para a verificação da referida lei é necessário classificar todas as palavras observadas no texto, de forma que as que possuem alta frequência de ocorrência sejam as primeiras da lista e, de forma decrescente, essa relação seja completada com as palavras de menor frequência de ocorrência. A palavra que apresentar maior frequência recebe o menor número da ordem de série e, à medida que as palavras vão diminuindo a frequência, os números de ordem vão aumentando. Após isso, deve-se obter a constante (c), a qual é resultado da multiplicação da ordem da série $(r$ ) pela frequência de ocorrência $(f)$, conforme demonstrado na Tabela 7.

Tabela 7 - Lei de Zipf

\begin{tabular}{ccc}
\hline Ordem de série $(\boldsymbol{r})$ & Frequência de ocorrência $(\boldsymbol{f})$ & Constante $(\boldsymbol{c}=\boldsymbol{r} \cdot \boldsymbol{f})$ \\
\hline 1 & 31 & 31 \\
\hline 2 & 26 & 52 \\
\hline 3 & 8 & 24 \\
\hline 4 & 7 & 28 \\
\hline 5 & 6 & 30 \\
\hline 6 & 4 & 24 \\
\hline 7 & 3 & 21 \\
\hline 8 & 2 & 16 \\
\hline 9 & 1 & 9
\end{tabular}

Fonte: Elaborada pelos autores.

Deve-se ressaltar que, usando as mesmas informações descritas na Tabela 7, é possível verificar a aplicação da referida lei por meio de um gráfico, no qual o eixo horizontal contém a ordem de série ( $r$ ), ao 
passo que o eixo vertical contém a frequência de ocorrência das palavras, conforme demonstrado na Figura 8.

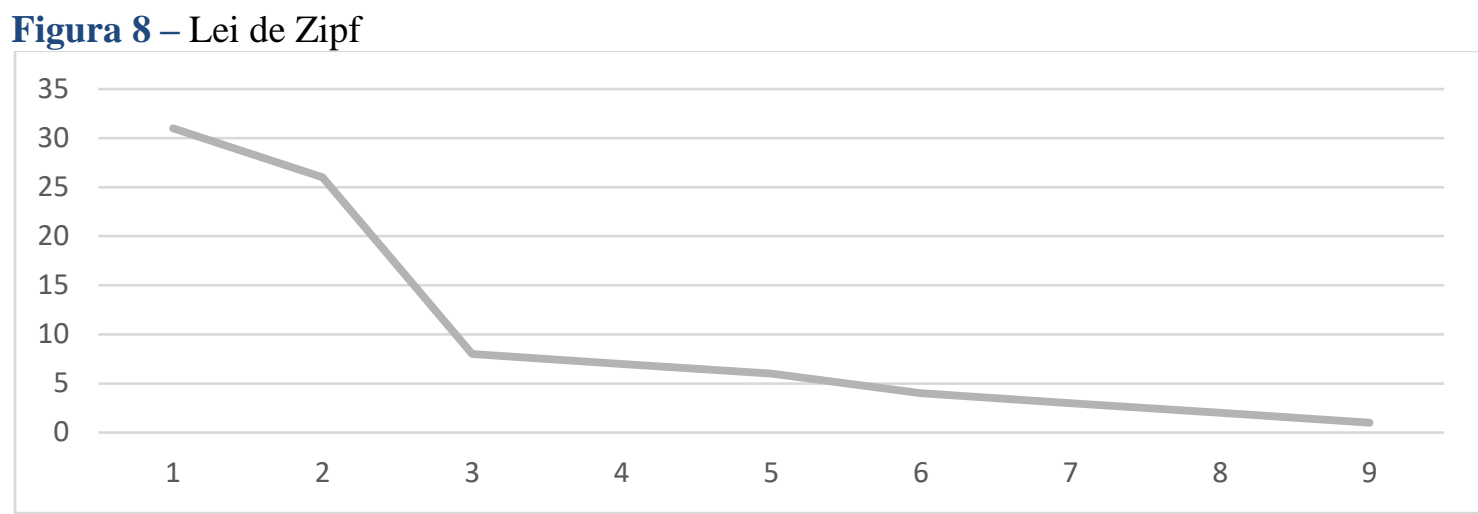

Fonte: Elaborada pelos autores.

Conforme demonstram a Tabela 5 e a Figura 8, algumas palavras possuem alta frequência, o que parece confirmar a validade da Lei de Zipf.

De acordo com Ferreira et al. (2019), outra forma de verificar a confirmação da referida lei pode ser feita por meio da elaboração de uma nuvem de palavras, na qual as palavras que apresentam maior frequência aparecem de forma destacada, como é o caso, por exemplo, da palavra Stakeholders na Figura 9. Os autores ressaltam, ainda, que a referida nuvem é importante para verificar quais os são principais termos usados em pesquisas sobre o tema.

A Figura 9 demonstra que esses termos são "Stakeholders", "teoria", "governança", "responsabilidade", "social”, "corporativa", "estratégia” e "gestão". Deve-se ressaltar que essas palavras, por vezes, aparecem juntas, de modo a formar os seguintes termos que figuram entre as palavras-chave de maior frequência: "Teoria dos Stakeholders", "responsabilidade social corporativa", "gestão de Stakeholders" e "governança corporativa". Um exemplo disso é o artigo de Filho, Souza, Lopes, Guimarães e Ponte (2019), cujas palavras-chave incluem "governança corporativa" e "responsabilidade social corporativa". 
Figura 9 - Nuvem de palavras

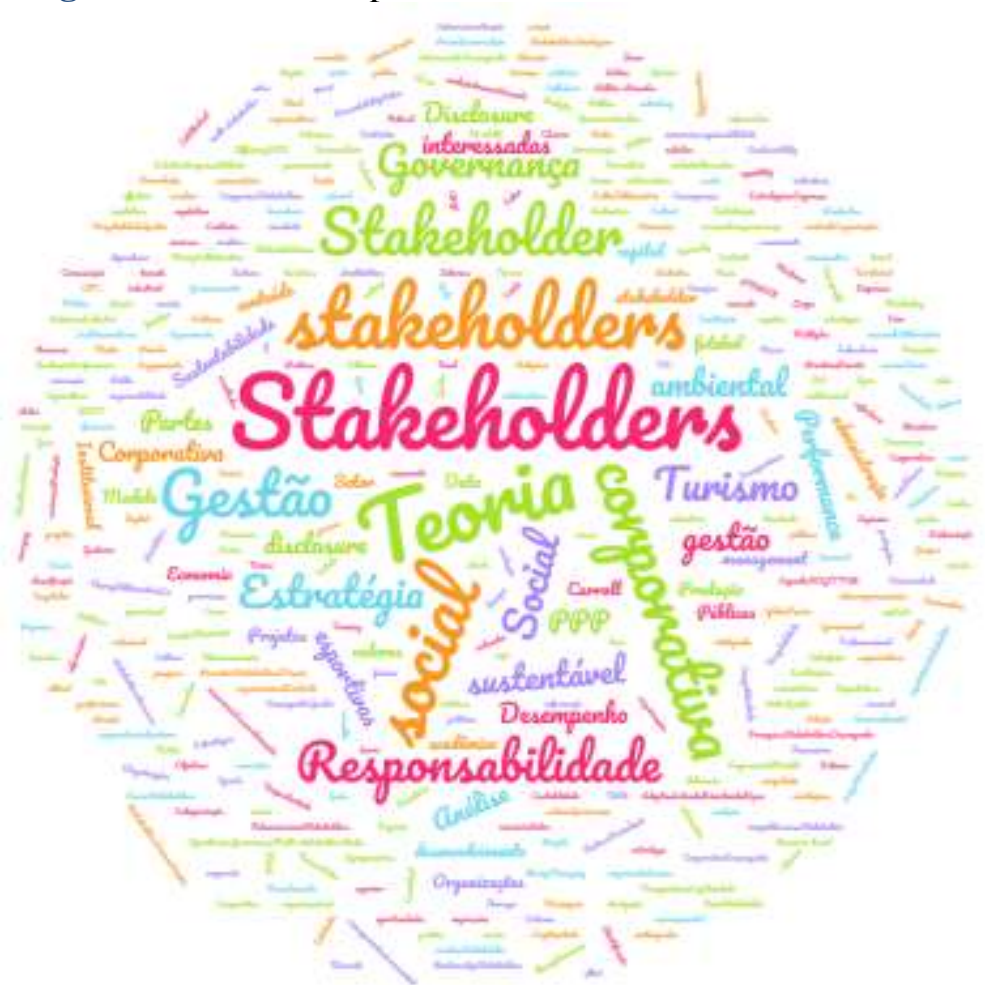

Fonte: Elaborada pelos autores.

Diante do exposto, é possível constatar que os resultados descritos nessa seção permitem identificar os principais periódicos e autores que publicam sobre o tema, bem como os métodos de coleta e análise de dados, e as categorias de análise por eles utilizados. Dessa forma, tais informações podem auxiliar os pesquisadores a visualizar tais aspectos metodológicos e conceituais relativos a esse campo teórico. Além disso, sugere-se que os próximos estudos considerem as lacunas e as tendências identificadas na literatura, as quais integram as recomendações para trabalhos futuros, apresentadas na sequência.

\section{Conclusões e recomendações para pesquisas futuras}

O objetivo desta pesquisa foi analisar o perfil dos estudos publicados recentemente em periódicos nacionais que utilizaram a Teoria dos Stakeholders. Os resultados demonstram que a produção acadêmica sobre o tema vem evoluindo e que a RBGN, a RAUFSM e a RIAE são os periódicos de referência. A maioria dos estudos examinados adota uma abordagem teórico-empírica, o que pode ser decorrência do fato de que a maioria dos estudos da amostra possui natureza qualitativa.

Além disso, a investigação sobre o tema é crescentemente colaborativa, sinalizando que pode estar ocorrendo uma consolidação de grupos de pesquisa, haja vista que a maioria dos estudos foi elaborada por dois ou mais autores. Ademais, é possível identificar a UNINOVE e a USP como as instituições de ensino que mais publicaram, e os autores Benny Kramer Costa e João Maurício Gama Boaventura, que, 
respectivamente, estão vinculados às universidades mencionadas como os autores que mais publicaram no período analisado.

Além disso, a compreensão de um fenômeno é o objetivo de estudo mais recorrente. Embora os estudos versem sobre os mais diversos setores da economia, constata-se uma maior incidência nos segmentos turismo, esportivo e educacional. Ademais, constatou-se que a pesquisa documental e a entrevista foram os instrumentos de coleta de dados mais utilizados, bem como que a análise de conteúdo foi a técnica de análise de dados mais usada, o que ratifica o predomínio de estudos de natureza qualitativa.

No que concerne às categorias de análise relacionadas com a Teoria dos Stakeholders, os resultados parecem corroborar a literatura, a qual afirma que a definição de Freeman (1984) tem sido a mais utilizada. Além disso, o modelo de identificação e análise de Stakeholder, proposto por Mitchell et al. (1997), foi o mais recorrente.

A análise dos resultados demonstra, ainda, que foi constatada a validade das Leis de Bradford e de Zipf, tendo em vista que foi possível observar uma concentração de artigos em um pequeno número de periódicos, bem como o fato de alguns termos possuírem alta frequência em comparação aos demais. Por outro lado, não foi possível confirmar a validade da Lei de Lotka, pois não foi possível confirmar a aplicação da Lei do Inverso do Quadrado e tampouco do parâmetro relativo a proporção dos autores que fazem uma única contribuição.

Os resultados demonstram, ainda, que é necessário maior rigor metodológico, pois, em uma quantidade significativa de artigos, não foram informados o modelo de análise e a definição de Stakeholder utilizados. Isso porque, em tais estudos, é citada a palavra Stakeholder sem, contudo, explicar o que significa tal conceito. Dessa forma, a ausência do referido rigor reduz a possibilidade de contribuição dos trabalhos para o avanço da referida teoria. Assim, é importante que estudos futuros explicitem definição e modelo utilizados, justificando a escolha.

Além disso, tendo em vista que apenas dois autores brasileiros (Gomes \& Gomes, 2015; Gomes et al., 2010) propuseram uma definição e um modelo de análise, sugere-se que os autores nacionais realizem uma reflexão sobre a necessidade de aprimoramento das definições ou modelos de análise existentes, de modo a não apenas melhorar a compreensão sobre a realidade brasileira, como também a contribuir para o avanço da teoria.

A pesquisa apresenta limitações, tendo em vista que a abrangência da amostra está limitada aos periódicos nacionais e aos estratos A2 a B2 do Qualis/CAPES. Assim, sugere-se que pesquisas futuras incluam artigos publicados em periódicos internacionais ou, ainda, ampliem os estratos (B3 e seguintes), de modo a aumentar a representatividade da amostra. Outra limitação decorre do fato de que as palavras usadas como critério de seleção da amostra foram pesquisadas no título, no resumo e entre as palavraschave. Assim, podem existir artigos que usaram a Teoria dos Stakeholders como referencial teórico, mas que não foram incluídos na amostra, pois não citaram as referidas palavras entre os elementos textuais mencionados. 
A análise dos resultados possibilita a identificação de lacunas na literatura. Nesse sentido, Barbero e Marchiano (2016) afirmam que a Teoria dos Stakeholders ainda é adolescente e precisa que algumas de suas proposições sejam testadas. Por esse motivo, sugere-se como agenda de pesquisa futura que sejam realizados estudos empíricos, visando testar hipóteses embasadas nas proposições da Teoria dos Stakeholders.

Nesse contexto, sugere-se que sejam realizados mais estudos como o de Bispo e Gomes (2018), os quais mapearam os Stakeholders envolvidos no processo de formulação de um programa do Governo Federal por meio da utilização do modelo de Savage et al. (1991). Estudos dessa natureza permitem identificar os interesses dos atores envolvidos com um programa governamental, permitindo aos gestores desenvolver estratégias que possam facilitar a implementação do referido programa.

Deve-se recordar que estudos sobre organizações públicas são oportunos, pois os Stakeholders são importantes para a gestão das atividades de qualquer organização, seja pública ou privada (Lugoboni, Salgado \& Murcia, 2019). Nesse sentido, parece existir uma oportunidade de pesquisa haja vista que apenas $7 \%$ dos estudos examinados dizem respeito às organizações do setor público.

A agenda proposta é consonante com o fato de que a identificação e a categorização dos Stakeholders, relacionando-os com os resultados alcançados pelas organizações, devem integrar a agenda futura de pesquisa sobre a Teoria de Stakeholders (Harrison et al., 2015). Isso pode ser feito por meio do emprego de alguns dos modelos de análise mencionados nesse estudo, o que demonstra a importância de revisões de literatura, como a realizada na presente pesquisa.

A análise dos resultados permite, ainda, a identificação de tendências, como é o caso do diálogo entre a Teoria de Stakeholders e o corpo de conhecimento sobre geração de valor, haja vista que o estado da arte da Teoria de Stakeholders está no debate sobre como criar valor (Freeman, Phillips \& Sisodia, 2020). Nesse contexto, recomenda-se que estudos futuros analisem o significado de valor para os diferentes atores, bem como a distribuição entre tais atores (Parmar et al., 2010; Harrison et al., 2015). Além disso, recomenda-se que sejam propostos aprimoramentos nos métodos de mensuração de valor (Brito \& Fazoli, 2019).

A atualidade dessa discussão está refletida no fato de que a definição de Stakeholder (Garcia-Castro \& Aguilera, 2015) e o modelo de análise (Harrison \& Bosse, 2013) mais recentes encontrados na amostra pesquisada abordam essa questão. Além disso, artigos publicados em 2019 corroboram essa tendência, como é o caso do de Brito e Fazoli (2019).

A agenda futura de pesquisa envolve também aspectos metodológicos. Nesse sentido, uma possibilidade diz respeito a aprimoramentos que possam potencializar o poder explicativo de modelos de análise de Stakeholders. Assim, por exemplo, sugere-se a criação de uma escala para mensurar os tipos de poder especificados por Mitchell et al. (1997). Além disso, o referido modelo pode, ainda, ser objeto de uma análise crítica a fim de questionar se as três dimensões (poder, legitimidade e urgência) contidas no modelo são suficientes para identificar os atores prioritários. 
Afirma-se isso, pois outros modelos contêm elementos que podem ser úteis nessa identificação. Por isso, uma recomendação para estudos futuros é a de que sejam utilizados simultaneamente mais um modelo de análise, pois isso permitirá demonstrar os múltiplos papéis desempenhados pelos atores, como, por exemplo, o papel na formulação e na implementação de políticas públicas (Gomes et al., 2010), o seu potencial de ameaça ou de cooperação (Savage et al., 1991) e o seu grau de importância (Mitchell et al., 1997).

Outra possibilidade de estudo futuro está relacionada à comparação internacional entre estudos que utilizaram diferentes modelos de análise de Stakeholders. Sugere-se, ainda, que novos estudos utilizem técnicas de análise de rede, permitindo compreender melhor a institucionalização da pesquisa sobre o tema no Brasil por meio, por exemplo, de redes de relacionamentos interinstitucionais.

\section{Referências}

Andriof, J. \& Waddock, S. (2002). Unfolding stakeholder engagement. In Andriof, J. Waddock, S. Husted, B. \& Rahman, S. S. (eds.) Unfolding stakeholder thinking: theory, responsibility and engagement. Sheffield: Greenleaf.

Araújo, C. A. (2006). Bibliometria: evolução histórica e questões atuais. Em Questão, 12 (1), 11-32.

Barbero, E. R. \& Marchiano, M. (2016). Stakeholders ou shareholders? Valores individuais de conselheiros e identidade empresarial. Revista Brasileira de Gestão de Negócios, 18 (61), 348-369.

Bispo, F. C. S. \& Gomes, R. C. (2018). Os papéis dos stakeholders na formulação do Pronatec. Revista de Administração Pública, 52 (6), 1258-1269.

Bourne, L. \& Walker, D. H. (2005). Visualising and mapping stakeholder influence. Management Decision, 43(5), 649-660.

Brito, S. C. \& Fazoli, D. A. (2019). Measuring value creation for stakeholders: a contribution from the empirical research. Revista Brasileira de Estratégia, 12 (2), 136-153.

Bryson, J. M. (1988). A Strategic Planning Process for Public and Non-profit Organizations. Long Range Planning, 21 (1), 73-81.

Cabral, S. Fernandes, A. \& Ribeiro, D. (2016). Os papéis dos stakeholders na implementação das parcerias público-privadas no Estado da Bahia. Cadernos EBAPE.BR, 14 (2), 325-339.

Carroll, A. B. (1991). The pyramid of corporate social responsibility: Toward the moral man-agement of organizational stakeholders. Business Horizons, 34, 39-48.

Carroll, A. B. \& Buchholtz, A. K. (2011) Business and society: ethics and stakeholder management. Mason-USA: South-Western Cengage Learning.

Clarkson, M. B. H. (1995). A stakeholder framework for analyzing and evaluating corporate social performance. Academy of Management Review, 20, 92-117. 
Cardoso, S. L. C. Sobrinho, M. V. \& Vasconcellos, A. M. A. (2015). Gestão ambiental de parques urbanos: o caso do Parque Ecológico do Município de Belém Gunnar Vingren. Revista Brasileira de Gestão Urbana, 7(1), 74-90.

Cintra, R. Amâncio-Vieira, S. Suzuki, T. \& Costa, B. (2014). Stakeholder theory: análise nos periódicos brasileiros a partir da bibliometria. Revista Portuguesa e Brasileira de Gestão, 13 (4), 43-55.

Curzon, R. (2009). Perceptions of stakeholder engagement-just what is it really?. International Journal of Green Economics, 3 (3-4), 271-284.

Donaldson, T. \& Preston, L. (1995). The stakeholder theory of the corporation: concepts, evidence and implications. Academy of Management Review, 20, 65-91.

Ferreira, R. M. Lima, S. L. L. Gomes, A. R. V. \& Mello, G. R. (2019). Governança Corporativa: um estudo bibliométrico da produção científica entre 2010 a 2016. Organizações em contexto, 15 (29), 323-342.

Filho, A. R. A. Sousa, A. L. C. Lopes, H. S. Guimarães, D. B. \& Ponte, V. M. R. (2019). Influência da internacionalização e da governança corporativa na responsabilidade social corporativa. Revista IberoAmericana de Estratégia, 18 (3), 397-419.

Fraga, A. M. Gemelli, C. E. \& Oliveira, S. R. (2019). Cenário das publicações científicas em carreira e gênero. Revista Pensamento Contemporâneo em Administração, 13 (3), 158-178.

Freeman, R. E. (1984). Strategic Management: A Stakeholder Approach, Massachusetts: Pitman.

Freeman R.E. (2010). Managing for Stakeholders: trade-offs or value creation. Journal of Business Ethics, 96, 7-9.

Freeman, R.E. (2017). Five challenges to stakeholder theory: a report on research in progress. In: Wasieleski, D. M., \& Weber, J. (ed.) Stakeholder Management Business and Society 360 (vol. 1, chap. 1, pp. 1-23), Bingley: Emerald Publishing Limited.

Freeman, R. E. (2020). About the Stakeholder Theory. Recuperado em 14 julho, 2020, de http://stakeholdertheory.org/about/.

Freeman, R. E. Phillips, R. \& Sisodia, R. (2020). Tensions in Stakeholder Theory. Business \& Society, 59 (2), 213-231.

Friedman, A. \& Miles. S. (2006). Stakeholders: theory and practice. Oxford: Oxford University Press.

Frooman, J. (1999). Stakeholder influence strategics. Academy of Management Review, 24 (2), 191-205.

Garcia-Castro, R. \& Aguilera, R. V. (2015). Incremental value creation and appropriation in a world with multiple Stakeholders. Strategic Management Journal, 36 (1), 137-147.

Godoy, A. C. (2013). Fundamentos de pesquisa qualitativa. In: Takahashi, A. R., W. (Org.). Pesquisa qualitativa em Administração: fundamentação, métodos e usos no Brasil. São Paulo: Atlas.

Gomes, R. C. \& Gomes, L. O. M. (2007). Proposing a theoretical framework to investigate the relationships between an organization and its environment. Revista de Administração Contemporânea, 11(1), 75-95. 
Gomes, R. C. \& Gomes, L. O. M. (2015). Search of a Stakeholder Management Theory for Third Sector Organizations. Contabilidade, Gestão e Governança, 18(1), 43-60.

Gomes, R. C. Liddle, J. \& Gomes, L. D. O. M. (2010). A five-sided model of stakeholder influence: a cross-national analysis of decision making in local government. Public Management Review, 12, 701724.

Gomes, R. C. Osborne, S. P. \& Guarnieri, P. (2020). Influências dos Stakeholders e desempenho do governo local: uma revisão sistemática da literatura. Revista de Administração Pública, 54 (3), 448467.

Guedes, V. L. S. \& Borschiver, S. (2005, junho). Bibliometria: Uma Ferramenta Estatística Para a Gestão da Informação e do Conhecimento, em Sistemas de Informação, de Comunicação e de Avaliação Científica e Tecnológica. Anais do VI Encontro Nacional da Ciência da Informação. Salvador, BA, Brasil. Recuperado em 5 setembro, 2020, de http://www.cinformanteriores.ufba.br/vi_anais/docs/VaniaLSGuedes.pdf.

Harrison, J. S. Bosse, D. A. (2013). How much is too much? The limits to generous treatment of Stakeholders. Business Horizons, 56 (30), 313-322.

Harrison, J. Freeman, E. \& Abreu, M. C. S. (2015). Stakeholder Theory as an ethical approach to effective management: applying the theory to multiple contexts. Revista Brasileira de Gestão de Negócios, 17 (55), 858-869.

Hatherly, D. Mitchell, R. K. Mitchell, J. R. \& Lee, J. H. (2020).

Reimagining profits and stakeholder capital to address tensions among stakeholders. Business \& Society, 59 (2), 322-350.

Hood, W. W. \& Wilson, C. S. (2001). The literature of bibliometrics, scientometrics, and informetrics. Scientometrics, 52 (2), 291-314.

Lugoboni, L. F. Salgado, B. S. F. \& Murcia, F. C. S. (2019). A evidenciação dos stakeholders nos formulários de referência: uma análise do foco das empresas do setor de saúde quando reportam seu risco. Revista Ibero-Americana de Estratégia, 18 (3), 420-437.

Kujala, J. Lehtimäki, H. \& Freeman. R. E. (2019). A stakeholder approach to value creation and leadership. In: Kangas, A. Kujala, J. Heikkinen, A. Lönnqvist, A. Laihonen, H. \& Bethwaite, J. (ed.) Leading change in a complex world: Transdisciplinary perspectives (chap. 7, pp. 123-143) Tampere: Tampere University Press.

Mainardes, H. A. \& Raposo, M. (2011). Stakeholder theory: issues to resolve. Management Decision, 49 (2), 226-252.

Mainardes, E. W. Alves, H. \& Raposo, M. (2015). The expectations and satisfaction levels of academic journals editors in their relationships with universities. Contextus - Revista Contemporânea de Economia e Gestão, 13 (1), 188-219.

Mascena, K. M. C. \& Stocker, F. (2020). Gestão de stakeholders: estado da arte e perspectivas. Future Studies Research Journal, 12 (1), 1-30.

Mason, R. O. Mitroff, I. I. (1981). Challenging strategic planning assumptions: theory, cases and techniques. NY: Wiley. 
Miragaia, D. A. M. Ferreira, J. J. M. \& Ratten, V. (2017). The strategic involvement of stakeholders in the efficiency of non-profit sport organisations: from a perspective of survival to sustainability. $B B R$. Brazilian Business Review, 14 (1), 42-58.

Mitchell, R. K. Agle, B. R. \& Wood, D. J. (1997). Toward a theory of stakeholder identification and salience: defining the principle of the who and what really counts. Academy of Management Review, 22, 853-886.

Mitchell, R. K. \& Lee, J. H. (2019). Stakeholder identification and its importance in the value creating system of stakeholder work. In: Harrison, J. S. Barney, J. B. Freeman, R. E. \& Phillips, R. A. (ed.) The cambridge handbook of Stakeholder Theory (chap. 4, pp. 53-74), Cambridge: Cambridge University Press.

Neutzling, D. M. Santos, M. S. D. \& Barcellos, M. D. (2015). Value Creation from Internationalization of Sugar Cane by-products: a multi-stakeholder view of artisanal cachaça production. Revista Brasileira de Gestão de Negócios, 17(55), 890-910.

Nóbrega, M. M. \& Cândido, G. A. (2015). Avaliação da performance social corporativa na ótica dos stakeholders: proposta de uma metodologia multidimensional. Revista de Gestão Social e Ambiental, 9 (2), 2-22.

Olander, S. (2007). Stakeholders impact analysis in construction projects management. Construction Management and Economics, 25(3), 277-287.

Oliveira, M. C. Pontes Junior, J. E. Oliveira, O. V. \& Sena, A. M. C. (2014). Análise comparativa da divulgação social de empresas francesas e brasileiras segundo a Teoria dos Stakeholders. BASE Revista de Administração e Contabilidade da UNISINOS, 11(4), 304-317.

Pagnussatt, D. Petrini, M. Silveira, L. M. \& Santos, A. C. M. Z. (2018). Quem são, o que fazem e como interagem: compreendendo os stakeholders em Pequenas Centrais Hidrelétricas Gestão e Produção, 25 (4), 888-900.

Parmar, B. L. Freeman, R. E. Harrison, J. S. Wicks, A. C. Purnell, L. \& Colle, S. (2010). Stakeholder Theory: the state of the art. The Academy of Management Annals, 4 (1), 403-445.

Pavão, Y. M. P. \& Rossetto, C. R. (2015). Stakeholder management capability and performance in brazilian cooperatives. Revista Brasileira de Gestão de Negócios, 17(55), 870-889.

Phillips, R. (1997). Stakeholder theory and a principle of fairness. Business Ethics Quarterly, 7 (1), p. 5166.

Reed, M. S. Graves, A. Dandy, N. Posthumus, H. Hubacek, K. Morris, J. Prell, C. Quinn, C. H. \& Stringer, L. C. (2009). Who's in and why? A typology of stakeholder's analysis methods for natural resource management. Journal of Environmental Management, 90(5), 1933-1949.

Ribeiro, H. C. M. \& Costa, B. C. (2017a). Influência dos stakeholders na gestão e no controle das organizações esportivas. Revista Ciências Administrativas, 23 (1), 42-69.

Ribeiro, H. C. M. \& Costa, B. C. (2017b). Stakeholders e sua influência na governança corporativa: um estudo de caso múltiplo em organizações esportivas. Ambiente Contábil, 9 (1), 246-267.

Rudzevicius, R. V. Boaventura, J. M. G. Mascena, K. M.C. \& Sarturi, G. (2018). Alocação de valor para os stakeholders: um estudo no setor financeiro. Revista de Administração da UNIMEP, 16 (1), 56-77. 
Savage, G. T. Nix, T. W. Whitehead, C. J. \& Blair, J. D. (1991). Strategies for assessing and managing organizational stakeholders. Academy of Management Executive, 5(2), 61-75.

Schepper, S. Dooms, M. \& Haezendonck, E. (2014). Stakeholder dynamics and responsibilities in public private partnerships: a mixed experience. International Journal of Project Management, 32(7), 12101222.

Silva, F. C. Shibao, F. Y. Santos, M. R. \& Barbieri J. C. (2019). Análise de stakeholders em indústria do setor plástico: uma aplicação da norma ABNT NBR ISO 14001:2015. Revista de Gestão Social e Ambiental, 13 (2), 40-57.

Takahashi, A. R. \& W. Semprebom, E. (2013). Resultados gerais e desafios. In: Takahashi, A. R., W. (Org.). Pesquisa qualitativa em Administração: fundamentação, métodos e usos no Brasil. São Paulo: Atlas.

Urbizagastegui, R. (2008). A produtividade dos autores sobre a Lei de Lotka, Ciência da Informação, 37 (2), 87-102.

Vieira, D. M. \& Gomes, R. C. (2014). Mudança Institucional Gradual e Transformativa: a Influência de Coalizões de Advocacia e Grupos de Interesses em Políticas Públicas. Organizações \& Sociedade, 21 (71), 679-694.

Voos, H. (1974). Lotka and Information Science. Journal of the American Society for Information Science, 25 (4), 270-272.

Voese, S. B. \& Mello, R. J. G. (2013). Análise bibliométrica sobre gestão estratégica de custos no Congresso Brasileiro de Custos: Aplicação da lei de Lotka. Revista Capital Científico, 11 (1), 1-19.

Wood, D. J. Mitchell, R. K. Agle, B. R. \& Bryan, L. M. (2018). Stakeholder identification and salience after 20 years: progress, problems, and prospects. Business \& Society, 1-50. 